Prepared in cooperation with the U.S. Department of Agriculture, Natural Resources Conservation Service, Wisconsin Department of Natural Resources, and Wisconsin Department of Health Services

\title{
Distribution and Variation of Arsenic in Wisconsin Surface Soils, With Data on Other Trace Elements
}

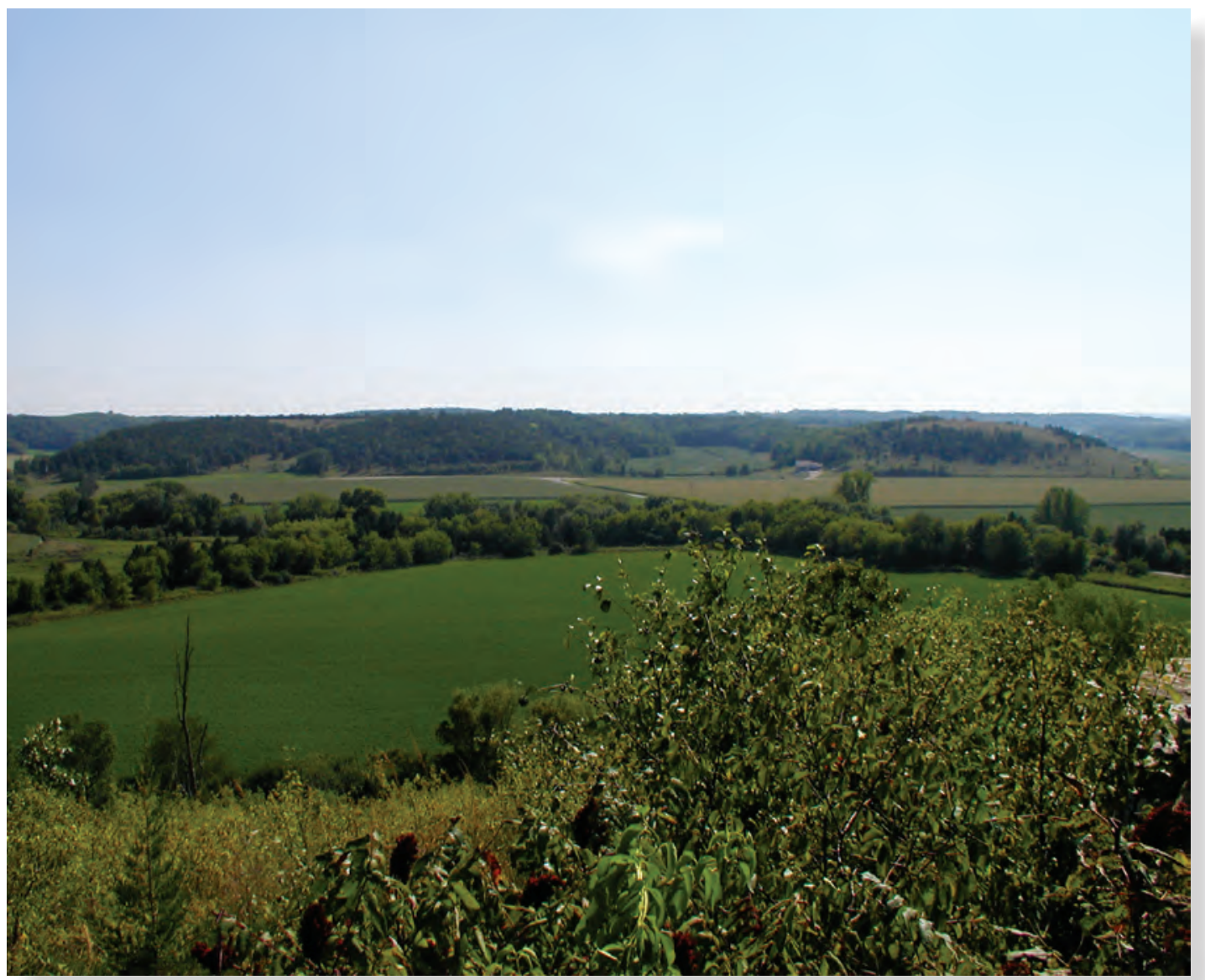

Scientific Investigations Report 2011-5202 



\section{Distribution and Variation of Arsenic in Wisconsin Surface Soils, With Data on Other Trace Elements}

By Krista A. Stensvold

Prepared in cooperation with the U.S. Department of Agriculture, Natural

Resources Conservation Service, Wisconsin Department of Natural Resources, and Wisconsin Department of Health Services

Scientific Investigations Report 2011-5202 


\title{
U.S. Department of the Interior \\ KEN SALAZAR, Secretary \\ U.S. Geological Survey \\ Marcia K. McNutt, Director
}

\author{
U.S. Geological Survey, Reston, Virginia: 2012
}

For more information on the USGS - the Federal source for science about the Earth, its natural and living resources, natural hazards, and the environment, visit http://www.usgs.gov or call 1-888-ASK-USGS.

For an overview of USGS information products, including maps, imagery, and publications, visit http://www.usgs.gov/pubprod

To order this and other USGS information products, visit http://store.usgs.gov

Any use of trade, product, or firm names is for descriptive purposes only and does not imply endorsement by the U.S. Government.

Although this report is in the public domain, permission must be secured from the individual copyright owners to reproduce any copyrighted materials contained within this report.

Suggested citation:

Stensvold, K.A., 2012, Distribution and variation of arsenic in Wisconsin surface soils, with data on other trace elements: U.S. Geological Survey Scientific Investigations Report 2011-5202, 41 p., 1 app. 


\section{Contents}

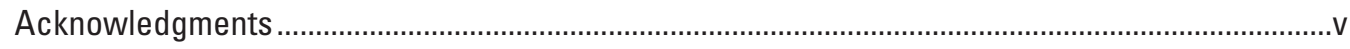

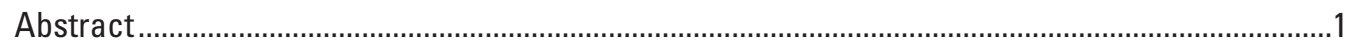

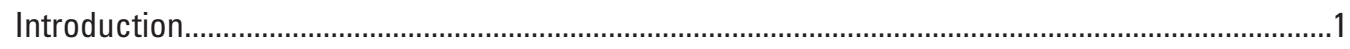

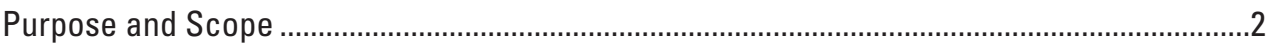

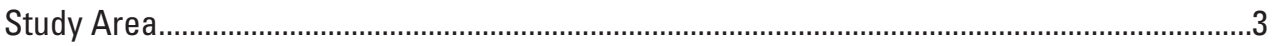

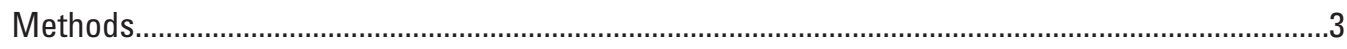

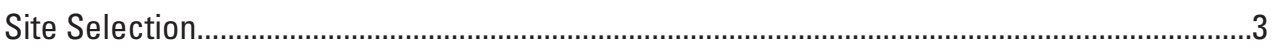

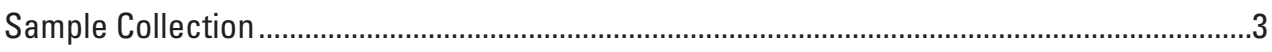

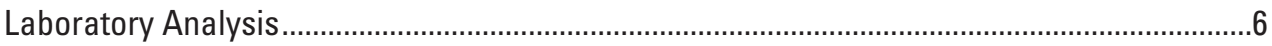

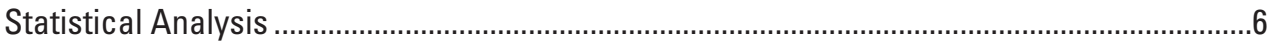

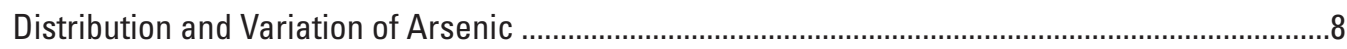

Statewide Arsenic Distribution ..........................................................................................

Comparison of Soil Arsenic Concentrations Across Geographic Regions .............................9

Comparison of Soil Arsenic Concentrations in Soil Groups ..................................................11

Data on Other Trace Elements ...................................................................................................11

Summary and Conclusions................................................................................................................

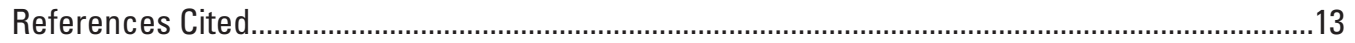

\section{Figures}

1. Boundaries of the geographic regions used for comparison of data in the arsenic baseline study.

2. Spatial distribution of arsenic concentrations of surface soil samples in Wisconsin

3. Statistical distribution of arsenic concentrations of surface soil samples in Wisconsin, categorized by the geographic regions shown in figure 1 and described in table 1, with outliers removed

4. Statistical distribution of arsenic concentrations of surface soil samples in Wisconsin, categorized by soil characteristic group described in table 2 , with outliers removed

\section{Tables}

1. Description of the geographic regions used for the arsenic baseline study, Wisconsin

2. Description of the soil-characteristic groups for the arsenic baseline study, Wisconsin

3. Seventeen trace elements included in the analysis by the Wisconsin State Laboratory of Hygiene for each soil sample taken in the arsenic baseline study. 
4. Statistical summary, including 95-percent upper confidence limit of the mean of arsenic data from surface soil samples in Wisconsin.

5. P-values from the Wilcoxon rank-sum test for comparing two sets of data on arsenic concentrations in Wisconsin surface soils

\section{Appendix Figures}

1-1. Facsimile of draft field procedure work plan for Wisconsin arsenic sampling project.

Maps showing spatial distribution of trace-element concentrations of surface

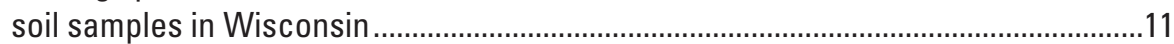

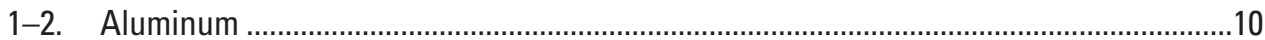

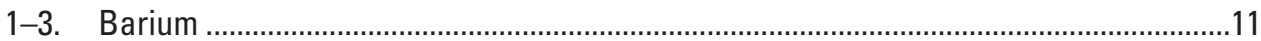

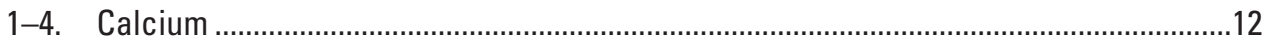

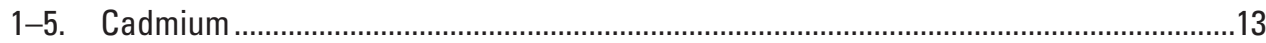

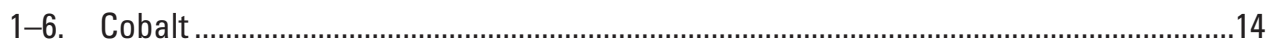

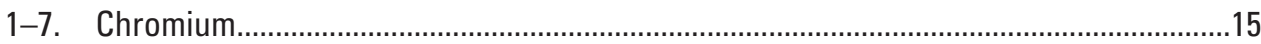

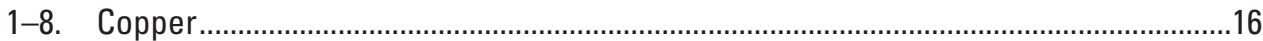

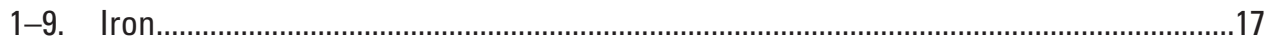

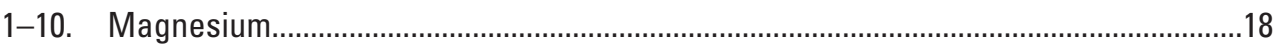

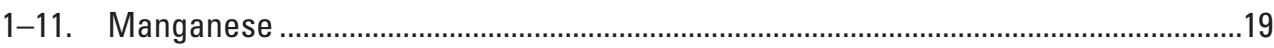

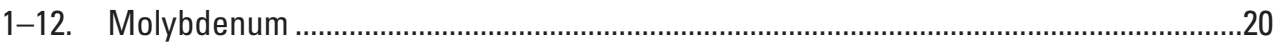

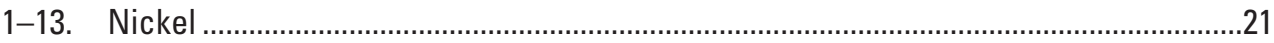

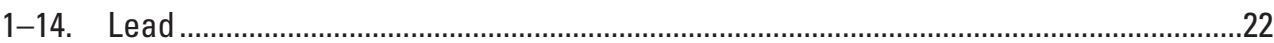

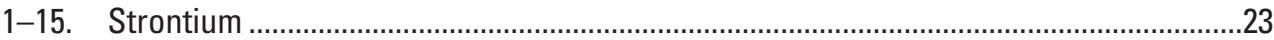

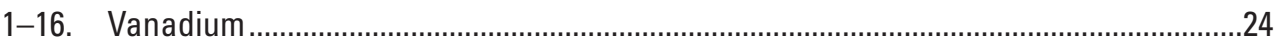

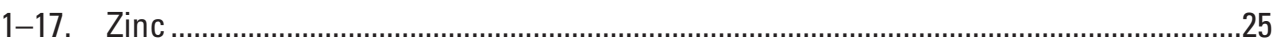

\section{Appendix Tables}

1-1. Complete dataset for arsenic baseline study.

This table, in Microsoft Excel format, is available for downloading at http://pubs.usgs.gov/sir/2011/5202/..

1-2. Statistical summary, including 95-percent upper confidence limit of the mean, of trace element data from surface soil samples in Wisconsin. 


\section{Acknowledgments}

The author would like to thank the soil scientists from the U.S. Department of Agriculture, Natural Resources Conservation Service for their assistance in the creation and implementation of the study design. Many thanks to Ed Lynch and Aristeo Pelayo from the Wisconsin Department of Natural Resources, David Hall and Douglas Causey from the U.S. Geological Survey, DeWayne Kennedy-Parker from the Wisconsin State Laboratory of Hygiene, and Henry NehlsLowe from the Wisconsin Department of Health Services for providing technical guidance during the report preparation. Also, thanks to Mike Eberle and Laurel Woodruff from the U.S. Geological Survey and Bruce Rheineck from the Wisconsin Department of Health Services for the valuable technical and editorial review comments that they gave on previous drafts, which helped improve this report greatly.

\section{Conversion Factors}

\begin{tabular}{lcl}
\hline \multicolumn{1}{c}{ Multiply } & \multicolumn{1}{c}{ By } & \multicolumn{1}{c}{ To obtain } \\
\hline inch (in.) & Length & \\
inch (in.) & 25.4 & millimeter $(\mathrm{mm})$ \\
foot (ft) & 2.54 & centimeter $(\mathrm{cm})$ \\
mile (mi) & 0.3048 & meter $(\mathrm{m})$ \\
\hline & 1.609 & kilometer $(\mathrm{km})$ \\
\hline acre & Area & \\
square mile $\left(\mathrm{mi}^{2}\right)$ & 0.4047 & hectare (ha) \\
\hline & 2.590 & square kilometer $\left(\mathrm{km}^{2}\right)$ \\
\hline gram (g) & Mass & \\
kilogram (kg) & 0.03527 & ounce, avoirdupois (oz) \\
\hline
\end{tabular}

Temperature in degrees Celsius $\left({ }^{\circ} \mathrm{C}\right)$ may be converted to degrees Fahrenheit $\left({ }^{\circ} \mathrm{F}\right)$ as follows: ${ }^{\circ} \mathrm{F}=\left(1.8 \times{ }^{\circ} \mathrm{C}\right)+32$

Temperature in degrees Fahrenheit $\left({ }^{\circ} \mathrm{F}\right)$ may be converted to degrees Celsius $\left({ }^{\circ} \mathrm{C}\right)$ as follows: ${ }^{\circ} \mathrm{C}=\left({ }^{\circ} \mathrm{F}-32\right) / 1.8$

Horizontal coordinate information is referenced to the World Geodetic System of 1984 (WGS 84). 



\title{
Distribution and Variation of Arsenic in Wisconsin Surface Soils, With Data on Other Trace Elements
}

\author{
By Krista A. Stensvold
}

\section{Abstract}

A total of 664 soil samples distributed among different geographic regions and soil types were collected across Wisconsin to describe the distribution of arsenic relative to parent material, soil texture, and drainage class. Soils from 6 inches in depth were composited, digested in aqua regia, and analyzed for 17 trace elements. Observed soil arsenic concentrations range from a high of 39 milligrams per kilogram $(\mathrm{mg} / \mathrm{kg})$ to less than the laboratory detection limit of $1 \mathrm{mg} / \mathrm{kg}$. Ten samples with soil arsenic concentrations greater than $8.5 \mathrm{mg} / \mathrm{kg}$ were determined to be significantly separate from the main cluster of the dataset. With these outliers removed, overall soil arsenic concentrations in Wisconsin have a median value of $1.8 \mathrm{mg} / \mathrm{kg}$, and the 95 -percent upper confidence limit of the mean is $2.4 \mathrm{mg} / \mathrm{kg}$.

Soils with sandy glacial outwash as a parent material have a lower median arsenic concentration $(1.0 \mathrm{mg} / \mathrm{kg})$ than soils forming in other parent materials ( 1.5 to $3.0 \mathrm{mg} / \mathrm{kg}$ ). Soil texture and drainage category also influence median arsenic concentration. Finer grained soils have a higher observed range of concentrations. For loamy and loess-dominated soil groups, drainage category influences the median arsenic concentration and observed range of values, but a consistent relationship within the data is not apparent. Statistical analysis of the 16 other elements are presented in this report, but the relationships of concentrations to soil properties or geographic areas were not examined.

\section{Introduction}

Arsenic, a trace element commonly found in surface soils, has both natural and anthropogenic sources. In uncontaminated soils, the most common natural source of arsenic is arsenic-bearing minerals in soil parent materials. Arsenicbearing minerals, such as glauconite, arsenopyrite, pyrite, and other sulfides, can weather in soils and release arsenic into the soil system. Arsenic-bearing minerals are commonly found in sedimentary rocks (Smith and others, 1998). Deposition from atmospheric sources of arsenic can contribute significantly to arsenic concentrations in soils. The ratio of atmospheric natural sources, such as volcanic activity, to atmospheric anthropogenic sources, such as fossil fuel combustion, varies regionally but on average their mutual contributions are about equal (O’Neill, 1995). Other non-atmospheric anthropogenic sources include industrial and mining waste products and agricultural applications (Smith and others, 1998). Elevated levels of arsenic in soils can compromise the health of the soil system as well as human health. The greatest risk to human health is through exposure that comes from arsenic that has leached from soils or bedrock into drinking-water sources (Das and others, 1996; Smith and others, 2000). Repeated exposure to arsenic at elevated concentrations can be toxic to the human system (Southworth, 1995; Das and others, 1996).

If known, baseline arsenic concentrations can be used as a guideline for assessing contamination levels of soils and may be part of the process of regulating the cleanup of contaminated soils. An element's baseline is defined as a range of concentrations around a mean, but the baseline does not strictly represent a natural background concentration because the range of values will also include contributions from nonpoint sources of anthropogenic arsenic (Gough, 1993; KabataPendis, 2001). States have used a variety of common statistics to characterize the baseline concentration in soils for cleanup purposes, including (1) the mean concentration (Illinois Environmental Protection Agency, 2007); (2) the 95th-percentile concentration (Vosnakis and others, 2009); and (3) the 95-percent upper confidence limit of the mean (Kentucky Energy and Environment Cabinet, 2004; Montana Department of Environmental Quality, 2005). However, existing data in most states are not abundant enough to properly estimate baseline arsenic concentrations.

Baseline concentrations can have natural variations that are influenced by a soil's physical and chemical properties. Arsenic availability in a soil system is controlled by chemical processes, mainly sorption, which is affected by specific physical and chemical soil properties. The presence of iron, aluminum, and manganese oxides increases the sorption of arsenic to soil surfaces (Elkhatib and others, 1984). Soil with fine-grained textures, such as clays, and soils with high organic matter content, such as wetland soils, have more exchange sites and thus have higher sorption capacity (Chen and others, 1999; Girouard and Zagury, 2009). Arsenic sorption on oxides, clays, and organic material can be influenced 
by $\mathrm{pH}$ (Frost and Griffen, 1977; Thanabalasingam and Pickering, 1986; Goldberg and Glaubig, 1988) and redox conditions (Kabata-Pendias, 2001).

Regional studies have quantified arsenic concentrations in soils with respect to parent material and soil physical and chemical properties. In New Jersey, soil samples were analyzed from three physiographic provinces: Valley and Ridge, Highlands, and Coastal Plain (Sanders, 2003). Mean arsenic concentrations of the Valley and Ridge and the Highlands provinces (4.98 and $6.04 \mathrm{mg} / \mathrm{kg}$, respectively) were found to be significantly different from that of the Coastal Plain province $(2.33 \mathrm{mg} / \mathrm{kg})$. It is assumed, given the study design, that these differences were due to differences in soil parent materials among the three provinces. A California study developed a comprehensive database of trace elements in soils to determine baseline concentrations in benchmark soils (Bradford and others, 1996). In that study, positive correlation coefficients for some elements (for example, iron-vanadium, nickel-chromium, and copper-cobalt) indicated that chemical and physical properties of soils and parent materials influenced trace element distribution within a soil. Other states have also attempted to identify variations in baseline concentrations on the basis of changes in soil texture and parent material (Michigan Department of Environmental Quality, 2005) and soil taxonomic orders and chemical characteristics (Chen and others, 2002). For example, Chen and others (2002) found that wetland soils in Florida had high arsenic concentrations, which were attributed to immobilization of arsenic by high concentrations of organic matter, iron and aluminum oxides, and clays that accumulated in wetlands.

A low-density geochemical soil survey of the United States (approximate spacing of one site per $6,000 \mathrm{~km}^{2}(2,300$ $\left.\mathrm{mi}^{2}\right)$ ) was completed by scientists from the U.S. Geological Survey (USGS). During this survey, soil samples were collected from a depth of about $20 \mathrm{~cm}$ (8 in.) across the conterminous United States from 1958 to 1976 (Boerngen and Shacklette, 1981; Shacklette and Boerngen, 1984). As part of the National Uranium Resource Evaluation Program (NURE), the Hydrogeochemical and Stream Sediment Reconnaissance (HSSR) component collected stream sediments across the conterminous United States between 1976 and 1984. The initial purpose of NURE was to identify potential uranium resources, but the scope was broadened to include analyses of additional elements, creating a second national-scale geochemical survey for the United States (Smith, 1997). Sampling density for the NURE program ranged from one sample per $10 \mathrm{~km}^{2}\left(3.9 \mathrm{mi}^{2}\right)$ to one sample per $23 \mathrm{~km}^{2}\left(8.9 \mathrm{mi}^{2}\right.$ ) (Information Systems Programs-Energy Resources Institute, 1985). Samples selected for a systematic reanalysis of NURE soil and stream sediment samples by the USGS to improve data quality have a sampling density of about one per $289 \mathrm{~km}^{2}\left(112 \mathrm{mi}^{2}\right)$. Data from these studies and more recent regional USGS geochemical baseline studies are available in the National Geochemical Survey database (U.S. Geological Survey, 2004). The National Geochemical Survey contains total elemental data from soil, stream sediment, and rock samples collected across the United
States, though stream sediment samples make up the majority of the data.

Soil analyses in the National Geochemical Survey database have been used to characterize regional soil composition. Grosz and others (2004) combined the U.S. data with an extensive Canadian geochemical database to create a map of arsenic concentrations. Their results show that typical arsenic concentrations in northern Wisconsin are less than $0.5 \mathrm{mg} / \mathrm{kg}$ and that the observed variability in surficial arsenic concentrations is controlled by bedrock characteristics. Cannon and others (2004) reanalyzed archived NURE stream sediment samples collected across northern Wisconsin. These data were compared to near-surface and subsurface soil samples collected from the same area to determine whether stream sediment samples could predict regional geochemical patterns in soils. Comparison of mean element concentrations of the three sample groups (stream sediments, surface soils, subsurface soils) showed that element concentrations among the groups were significantly different from one another. However, with some statistical manipulation that included multiple-sample averaging and smoothing, stream sediment data could be extrapolated to soil compositions for some elements (Cannon and others, 2004). Thus, in the absence of a high-density soil geochemical dataset, element concentration predictions based on stream sediment geochemistry could be used for regional background concentrations for some elements (Cannon and others, 2004).

Despite these efforts to collect and compile a comprehensive geochemical database, sufficient data do not exist to determine baseline reference values for all of Wisconsin's soils. The USGS, in cooperation with the U.S. Department of Agriculture, Natural Resources Conservation Service (NRCS), Wisconsin Department of Natural Resources (WDNR), and Wisconsin Department of Health Services, designed this study to collect trace element data from samples that are representative of all soils types and parent material sources in the State of Wisconsin. Data from this study will be used to characterize the baseline concentration of arsenic and any variation in this baseline value that may be a result of changing soil physical and chemical properties or parent material.

\section{Purpose and Scope}

The objective of this report is to describe the distribution of arsenic in Wisconsin surface soils and identify potential systematic variations of arsenic concentrations with respect to soil properties or parent materials. This information about the distribution and controls on arsenic concentrations in soils across Wisconsin could be helpful for the determination of regulatory levels of arsenic in soils. Sampling and analytic methods were designed to exclude obvious anthropogenic influences to achieve values that are as close as possible to a natural baseline while recognizing that few areas are pristine.

Data from this study are not directly comparable to the geochemical data in the USGS National Geochemical 
database. The samples in this study were analyzed by using an aqua regia partial digestion technique rather than a fouracid total digestion method that was common for the NURE program and the soils collected for the Shacklette and Boerngen (1984) survey. The partial digestion method was used as results from this analytical method are indicative of the environmentally available fraction for each element and are thus more comparable to values required by the regulatory community.

\section{Study Area}

The state of Wisconsin comprises approximately 35 million acres. Glaciers played a significant role in the formation of both the landscape and the soils. Three-fourths of the soils in the State are forming in glacial deposits made up of sand and gravel derived from glacial outwash, loamy glacial tills, or glacial lacustrine sediments, whereas the remainder of the soils are developing in either loess deposits or bedrock residuum (Syverson and Colgan, 2004; U.S. Department of Agriculture, 2006). Sampling for this study focused on soils under natural vegetation regimes that ranged from forest to wetland to prairie and avoided soils forming under disturbed agricultural and urban landscapes (Hole, 1976).

\section{Methods}

\section{Site Selection}

The site selection and soil sampling for this project were done by the NRCS, and were designed to meet two objectives. The first objective was to represent the major variations in soil type and parent material proportional to their current areal extent. The second objective was to sample locations that would best represent naturally occurring arsenic concentration in surface soils. The target sample count was 650 samples, resulting in a sampling density of 1 sample per $84 \mathrm{mi}^{2}$. A detailed description of the site selection and sampling plan is given in the appendix (fig. 1-1).

To meet the first study objective, the State was divided into six geographic regions; within each of the six regions, soils were assigned into nine soil groups on the basis of parent material, surface texture, and drainage. The six geographic regions are based on differences in parent material, primarily influenced by glacial history, including time interval of glacial advance and direction of flow representing differences in source and age of parent material. The six regions are (1) Copper Falls Formation (2) Green Bay Lobe, (3) Lake Michigan Lobe, (4) Central Sands, (5) Driftless Area, and (6) Des Moines Lobe. These regions are shown in figure 1, and brief descriptions of the parent materials (Syverson and Colgan, 2004) and glacial history (Clayton and others 2006) are listed in table 1 .
The different soil series in Wisconsin were placed into nine soil groups based on a combination of parent material, surface layer texture, and NRCS drainage classification of the series (U.S. Department of Agriculture, Soil Survey Staff, 1993). Detailed descriptions of the nine soil groups are listed in table 2. The soil groups were sampled in proportion to their areal extent within a geographic region, with a minimum of two samples per soil group per region.

Actual sampling locations were determined in the field and were selected with reference to the following criteria to fulfill the second objective of this study:

1. Must be in a forested lot, permanent pasture, or otherwise undisturbed area at least $20 \mathrm{ft}$ away from a fence line.

2. Must not be within $1 \mathrm{mi}$ of any other arsenic study sample site.

3. Must not be within $5 \mathrm{mi}$ of any other sample from the same soil group.

4. Must not be within $100 \mathrm{ft}$ of existing known historical construction site or disturbed area (such as roads, dumps, pits, pipelines, or homesites).

5. Must not be within $300 \mathrm{ft}$ of a potential source of contamination (for example, past or present orchard or vegetable growing area; cattle-dipping sites; wood preservation activities; grasshopper bait; land that has had poultry or swine manure, sewage waste, or paper mill sludge applied to it; areas listed by the WDNR Bureau for Remediation and Redevelopment Tracking System).

These guidelines were followed as closely as possible, although in some cases it was not possible to meet all five criteria.

\section{Sample Collection}

Samples were collected at 664 locations across Wisconsin during late fall 2006 and spring, summer, and fall 2007. Following field selection of an appropriate sampling location, a brief in-field description and classification (to the series level) of the soil profile at the sampling site was done prior to sampling. This step provided field verification of soil series and, therefore, soil group. Geographic coordinates were recorded for each site with a handheld global positioning system (GPS). A sample was taken from the upper 6 inches of the soil profile, first discarding by hand any overlying undecomposed organic material as well as any coarse fragments contained within the sample. The samples were collected with a stainless steel spade and stored in laboratorygrade plastic bags. At 62 locations (approximately 10 percent of the sites), two samples were collected, composited, and then split. These field duplicate samples were submitted to the same laboratory as the primary samples for quality-assurance purposes. 


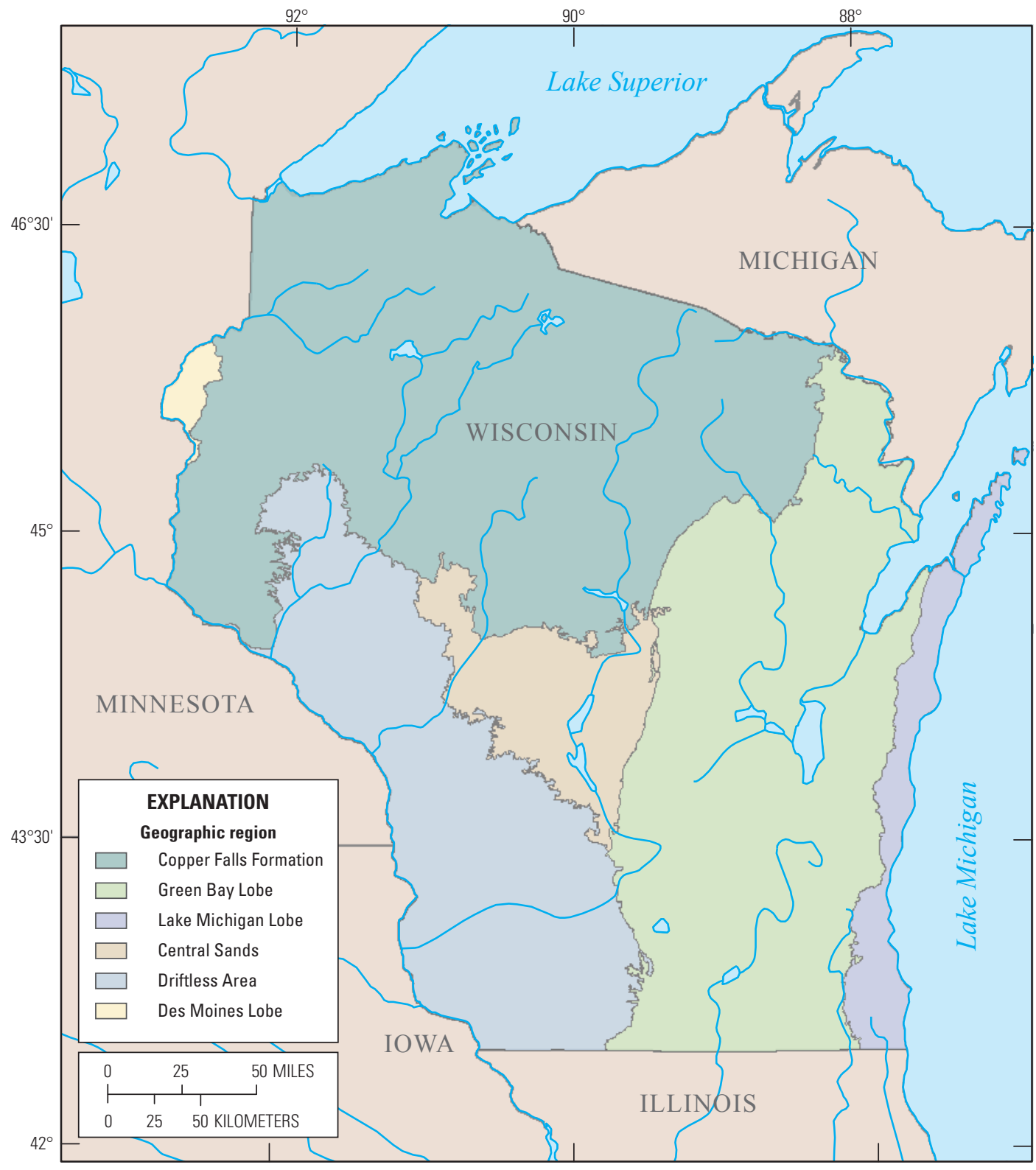

Figure 1. Boundaries of the geographic regions used for comparison of data in the arsenic baseline study. 
Table 1. Description of the geographic regions used for the arsenic baseline study, Wisconsin.

[\%, percent of State area; ka, kiloannum (thousands of years ago)]

\begin{tabular}{|c|c|c|c|c|}
\hline Geographic region & Area $(\%)$ & $\begin{array}{l}\text { Most recent glacial } \\
\text { deposition (ka) }\end{array}$ & Parent material ${ }^{1}$ & $\begin{array}{l}\text { Direction of glacial } \\
\text { advance }^{2}\end{array}$ \\
\hline Copper Falls Formation & 39.6 & $26-14$ & $\begin{array}{l}\text { Lacustrine silts and clays in the northwest, } \\
\text { sandy tills in the remaining area. }\end{array}$ & South-southwest \\
\hline Green Bay Lobe & 29.9 & $25-9$ & $\begin{array}{l}\text { Clay tills in northeast and sandy tills in } \\
\text { southwest. }\end{array}$ & Southwest \\
\hline Lake Michigan Lobe & 4.0 & $25-9$ & Fine-textured tills. & Southwest \\
\hline Central Sands & 6.8 & $19-14$ & Unconsolidated sand, glacial outwash. & - \\
\hline Driftless Area & 19.1 & - & Loess, residuum. & - \\
\hline
\end{tabular}

${ }^{1}$ Syverson and Colgan, 2004.

${ }^{2}$ Clayton and others, 2006.

Table 2. Description of the soil-characteristic groups for the arsenic baseline study, Wisconsin.

[Drainage category: $\mathrm{PD}$, poor to very poor drainage; $\mathrm{WD}$, somewhat poor to excessive drainage]

\begin{tabular}{ll}
\hline \multicolumn{1}{c}{ Soil group } & \multicolumn{1}{c}{ Soil texture } \\
\hline PD, Loess & Loess or loess derived silts. \\
WD, Loess & Loess or loess derived silts. \\
PD, Sand & Sand or loamy sand. \\
WD, Sand & Sand or loamy sand. \\
PD, Clay & Sandy clay, clay, clay loam, silty clay loam, or silty clay. \\
WD, Clay & Sandy clay, clay, clay loam, silty clay loam, or silty clay. \\
PD, Loam & Silt, silt loam, loam, or sandy loam. \\
WD, Loam & Silt, silt loam, loam, or sandy loam. \\
Organic & Organic soils. \\
\hline
\end{tabular}




\section{Laboratory Analysis}

Samples were sent to the Wisconsin State Laboratory of Hygiene (WSLH) for chemical analysis of 17 trace elements (table 3). Individual samples were oven-dried at $103^{\circ} \mathrm{C}$, sieved to less than $2 \mathrm{~mm}$ (about $0.079 \mathrm{in}$ ), and ground to increase subsample homogeneity for analysis. An aliquot of each sample was refluxed in nitric and hydrochloric acid to bring a number of elements into aqueous solution. This type of aqua regia partial digestion results in an extract from which the total recoverable portion of a particular element can be measured and excludes the portion of that element that resides in the silicate structure of soil minerals. The extraction solution was analyzed for 17 trace elements by using inductively coupled plasma-atomic emission spectrometry (ICP-AES; Method 200.7, U.S. Environmental Protection Agency, 1994). The resulting concentration is considered to represent the environmentally available portion of a trace element that would be available for biological uptake or mobile within the soil system under ideal conditions.

Analytical precision was calculated by taking the average percent difference between duplicate samples (table 3). Duplicate pairs were included in the overall average only if both samples had values above the detection limit. Average

Table 3. Seventeen trace elements included in the analysis by the Wisconsin State Laboratory of Hygiene for each soil sample taken in the arsenic baseline study. (Calculations of analytical precision values are described in the laboratory methods section.)

[mg/kg, milligrams per kilogram; \%, percent]

\begin{tabular}{lcc}
\hline \multicolumn{1}{c}{ Element } & $\begin{array}{c}\text { Detection limit } \\
(\mathbf{m g} / \mathbf{k g})\end{array}$ & $\begin{array}{c}\text { Analytical precision } \\
(\%)\end{array}$ \\
\hline Aluminum & 1.0 & 14 \\
Arsenic & 1.0 & 25 \\
Barium & 0.5 & 20 \\
Calcium & 10 & 26 \\
Cadmium & 0.1 & 38 \\
Chromium & 0.5 & 14 \\
Cobalt & 0.5 & 17 \\
Copper & 0.5 & 24 \\
Iron & 10 & 17 \\
Lead & 1.0 & 25 \\
Magnesium & 10 & 17 \\
Manganese & 0.1 & 20 \\
Molybdenum & 1.0 & 18 \\
Nickel & 0.5 & 13 \\
Strontium & 0.5 & 20 \\
Vanadium & 0.5 & 15 \\
Zinc & 0.5 & 18 \\
\hline
\end{tabular}

precision percentages for each of the trace elements ranged from 14 and 38 percent. For this study, one source of error in analytical precision is the general heterogeneity of the soil matrix. The way that a specific trace element is distributed within a soil sample depends largely on particle size and organic matter concentration. An unequal distribution of these characteristics within each subsample split can cause disparity between analytical results for the same field sample. Another source of error that is specific to the arsenic data is low concentrations relative to the method detection limit. The limit of quantification for this method when analyzing arsenic is $3 \mathrm{mg} / \mathrm{kg}$. When a value drops below this limit but is above the method limit of detection of $1 \mathrm{mg} / \mathrm{kg}$, uncertainty is high and variability can also be high (D. Kennedy-Parker, Wisconsin State Laboratory of Hygiene, written commun., 2008). Additionally, when overall trace element concentrations are particularly low, uncertainty can be attributed to spectral interferences, which will result in a sample having a negative result. In most cases, compensation for such interference can be used to adjust a value and report a corrected concentration given for a sample. Of the 733 primary and duplicate samples analyzed, 120 were reported as negative values, possibly as a result of this interference (D. Kennedy-Parker, Wisconsin State Laboratory of Hygiene, written commun., 2009).

As a result of the high level of variability in our dataset and the high incidence of "censored" or "non-detect" values (that is, values reported as less than the method detection limit), we examined our data to determine which samples to include in a subset of samples that would be submitted to the WSLH for reanalysis. Samples that were chosen included those with a reported arsenic concentration greater than $8 \mathrm{mg} / \mathrm{kg}$, a portion of the samples reported as non-detect values, and main and duplicate samples whose concentrations had an absolute difference of $1 \mathrm{mg} / \mathrm{kg}$ or greater. In 2009, a subset of 81 samples from the original 726 samples was reanalyzed, and results are included in the appendix, in table 1-1. Columns are labeled with a "2" after the type of sample in the heading, for example, As_value_main2. Where applicable, the results of the reanalysis were compared to the corresponding primary sample data, and the higher of the two concentrations was used in statistical calculations. These final arsenic values are labeled in appendix table 1 as As_value final.

\section{Statistical Analysis}

All statistics were calculated by using the ProUCL statistical package (U.S. Environmental Protection Agency, 2010). ProUCL is a public domain software package released by the U.S. Environmental Protection Agency for environmental datasets in support of site evaluation, risk assessments, and cleanup regulations. This software was created for critical statistical concerns in any baseline concentration study and is designed to (1) manipulate censored datasets, (2) test and identify outliers, and (3) identify data distribution. The ProUCL software has several parametric and 
nonparametric statistical methods that can be used to estimate upper limits and upper percentiles, commonly used to estimate baseline threshold values of datasets, including censored datasets. The test for outliers is separate from the calculation of upper limits and percentiles, so after removal of the outliers, another iteration is necessary to determine the higher-order statistics.

The main objective of using statistics in this study was to model the majority of the arsenic data representing the main dominant population rather than to accommodate high outlying observations that may yield inflated higher-order statistics. Multiple summary statistics were calculated for the entire dataset as well as subsets of the data defined by the geographic and soil groups described in tables 1 and 2. The fundamental assumptions for calculating upper confidence limits of the mean (UCL) are that all of the data belong to a single population and that outliers are removed (Singh and others, 2006). The Wisconsin soil arsenic dataset did not have either a parametric or lognormal distribution, so nonparametric methods were used when applicable. Prior to calculating summary statistics, outliers were identified using Rosner's outlier test. The outliers in all cases were unusually large values and were removed on the assumption that the sample represented a site that was likely more heavily influenced by anthropogenic sources of arsenic than was desired for the purposes of this study. At the 1-percent significance level a total of 10 outliers were removed (samples with concentrations greater than $8.5 \mathrm{mg} / \mathrm{kg}$ ), leaving 654 samples in the dataset for further statistical analysis. After the outliers were removed we calculated raw summary statistics, including 90th, 95th, and 99th percentiles, on the dataset that remained. Owing to the nature of the dataset and laboratory analysis method, there was a large percentage of samples with arsenic concentrations below the laboratory detection limit of $1 \mathrm{mg} / \mathrm{kg}$ (table 4). ProUCL has multiple censored data methods available depending on data distribution and the level of censoring within a dataset. For this study we used the Kaplan-Meier estimation with bias-corrected bootstrap method for computing the 95-percent upper confidence limit. The choice of this method was based on guidance in Singh and others (2006). The nonparametric Wilcoxon rank-sum test was used to determine whether significant differences exist in the distributions of arsenic data among individual geographic regions or soil groups. This test is quite similar to the more common student's t-test but is more robust if data are not normally distributed. All statistics, outlier tests, and summary statistics were applied to the other 16 trace elements, and results are listed in the appendix (table 1-2). Data for molybdenum had a very high percentage of nondetects (91 percent; appendix, table 1-2), so outlier tests and most summary statistics for that element were unable to be estimated with the methods used in this study.

Table 4. Statistical summary, including 95-percent upper confidence limit of the mean (95\% UCL) of arsenic data from surface soil samples in Wisconsin. Summaries for the entire data set and for groups described in tables 1 and 2 were calculated after outliers were removed.

$[\%$, percent; PD, poor to very poor drainage; WD, somewhat poor to excessive drainage; CFF, Copper Falls Formation; GBL, Green Bay Lobe; LML, Lake Michigan Lobe; CS, Central Sands; DA, Driftless Area; DML, Des Moines Lobe]

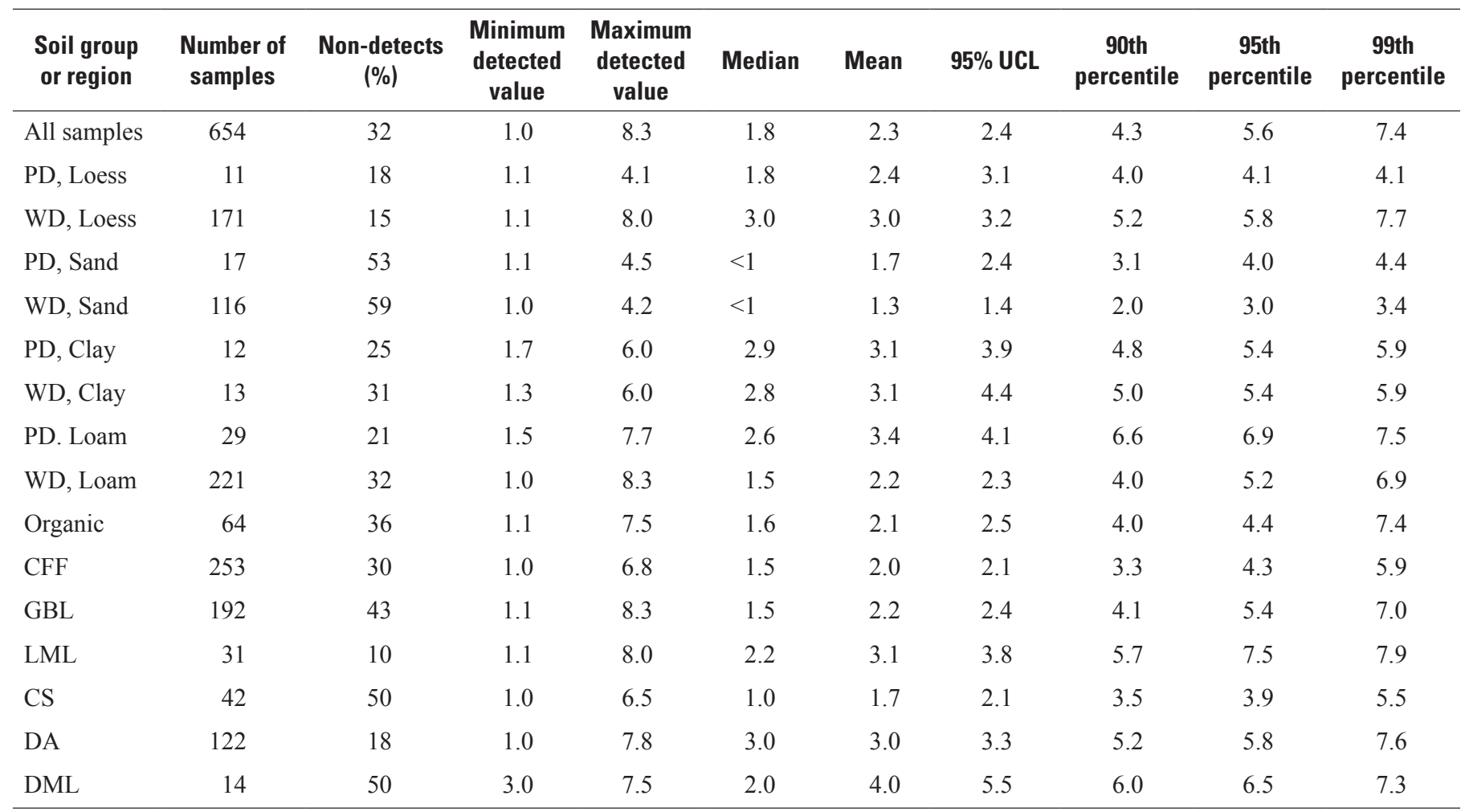




\section{Distribution and Variation of Arsenic}

\section{Statewide Arsenic Distribution}

Concentrations of arsenic in surface soils for the entire state of Wisconsin ranged from a high of $39 \mathrm{mg} / \mathrm{kg}$ to values below the laboratory detection limit $(1 \mathrm{mg} / \mathrm{kg}$, table 4$)$. Because samples with arsenic values greater than $8.5 \mathrm{mg} /$ $\mathrm{kg}$ were determined to be outliers and removed from the dataset prior to calculation of summary statistics (appendix, table 1-1), the total number of samples used for the statistical analysis is 654 . Of those 654 samples, 210 had concentrations below the detection limit of $1 \mathrm{mg} / \mathrm{kg}$. The median value for the dataset ( $\mathrm{n}=654$ ) was $1.8 \mathrm{mg} / \mathrm{kg}$, and the calculated mean was $2.3 \mathrm{mg} / \mathrm{kg}$. The 95 -percent upper confidence limit of the mean was $2.4 \mathrm{mg} / \mathrm{kg}$ and the, 90th, 95th, and 99th percentiles were $4.3,5.6$, and $7.4 \mathrm{mg} / \mathrm{kg}$, respectively (table 4). Figure 2 shows the sampling locations for the study; symbols on the map represent one of four arsenic concentration-based groups, as well as outliers. The first concentration group $(<1.0 \mathrm{mg} / \mathrm{kg})$, signified by an open box symbol, represents the sample sites where arsenic values were below the method detection limit.

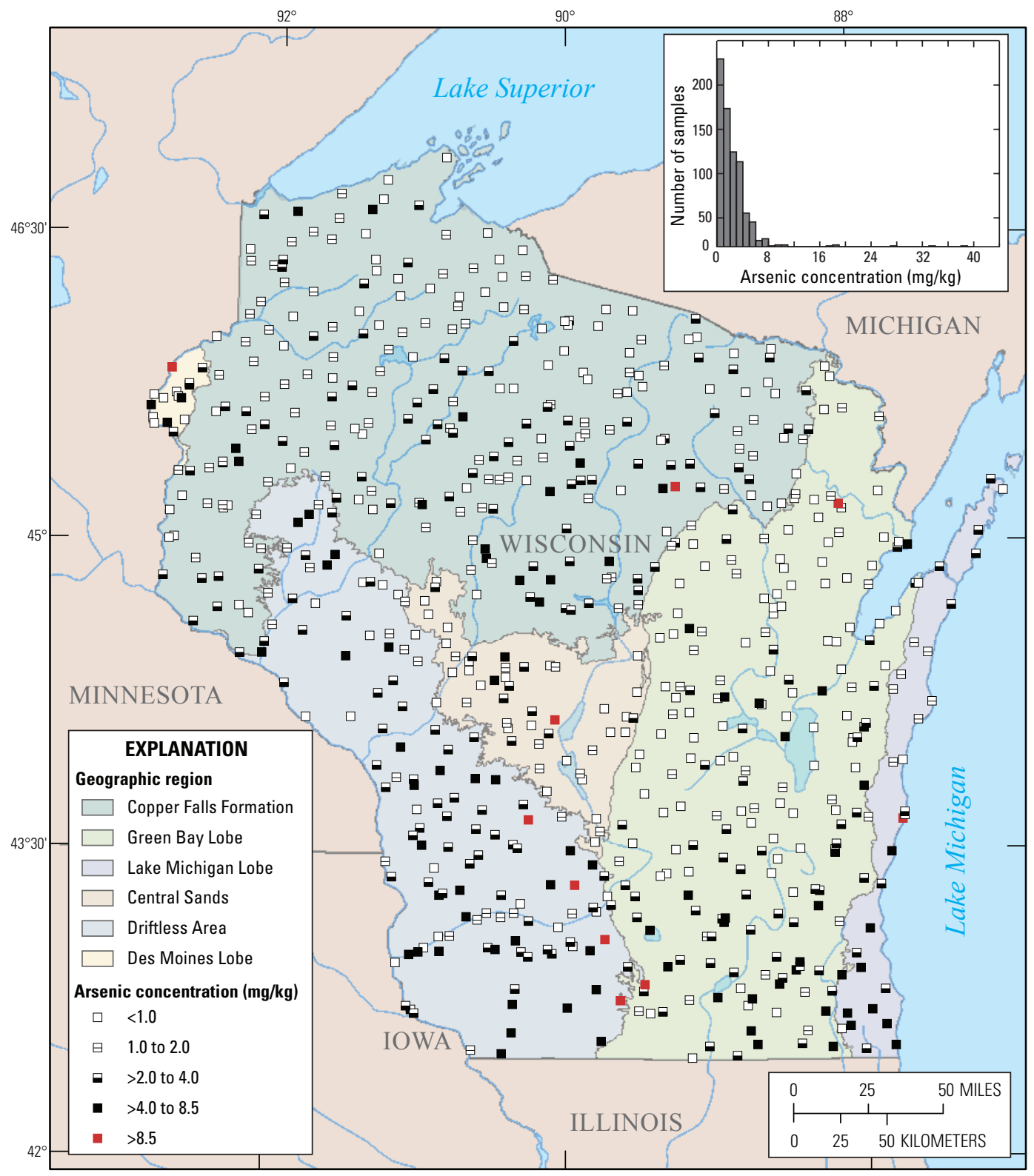

Figure 2. Spatial distribution of arsenic concentrations of surface soil samples in Wisconsin. The histogram in the figure shows the frequency distribution of the arsenic concentrations. Data displayed in both the map (red squares) and the histogram include outliers that were removed prior to statistical analysis. (mg/kg, milligrams per kilogram) 
Outlier values are shown as red box symbols (concentration $>8.5 \mathrm{mg} / \mathrm{kg}$ ). The remainder of the samples are broken into three additional arsenic concentration-based groups (1.0 to $2.0 \mathrm{mg} / \mathrm{kg},>2.0$ to $4.0 \mathrm{mg} / \mathrm{kg}$, and $>4.0$ to $8.5 \mathrm{mg} / \mathrm{kg}$ ). There are noticeable spatial patterns in arsenic concentrations across the State (fig. 2). In the north and central parts, arsenic concentrations are in the lower concentration ranges, whereas in the southwest and southeast parts, concentrations are in the higher concentration ranges of observed values. The histogram in figure 2 shows the frequency distribution of arsenic values, and the substantial positive skew in the dataset indicates relatively low arsenic concentrations.

\section{Comparison of Soil Arsenic Concentrations Across Geographic Regions}

Boxplots illustrating the distribution of arsenic within each of the six geographic regions (fig. 3) show that the range and median arsenic values of the Copper Falls Formation and Green Bay Lobe regional datasets are quite similar and could possibly be placed into a single group (table 4). Cental Sands soils have a significantly lower range of arsenic concentrations, with the median value at the detection limit of $1 \mathrm{mg} / \mathrm{kg}$. This can be attributed to the sandy-textured soils that

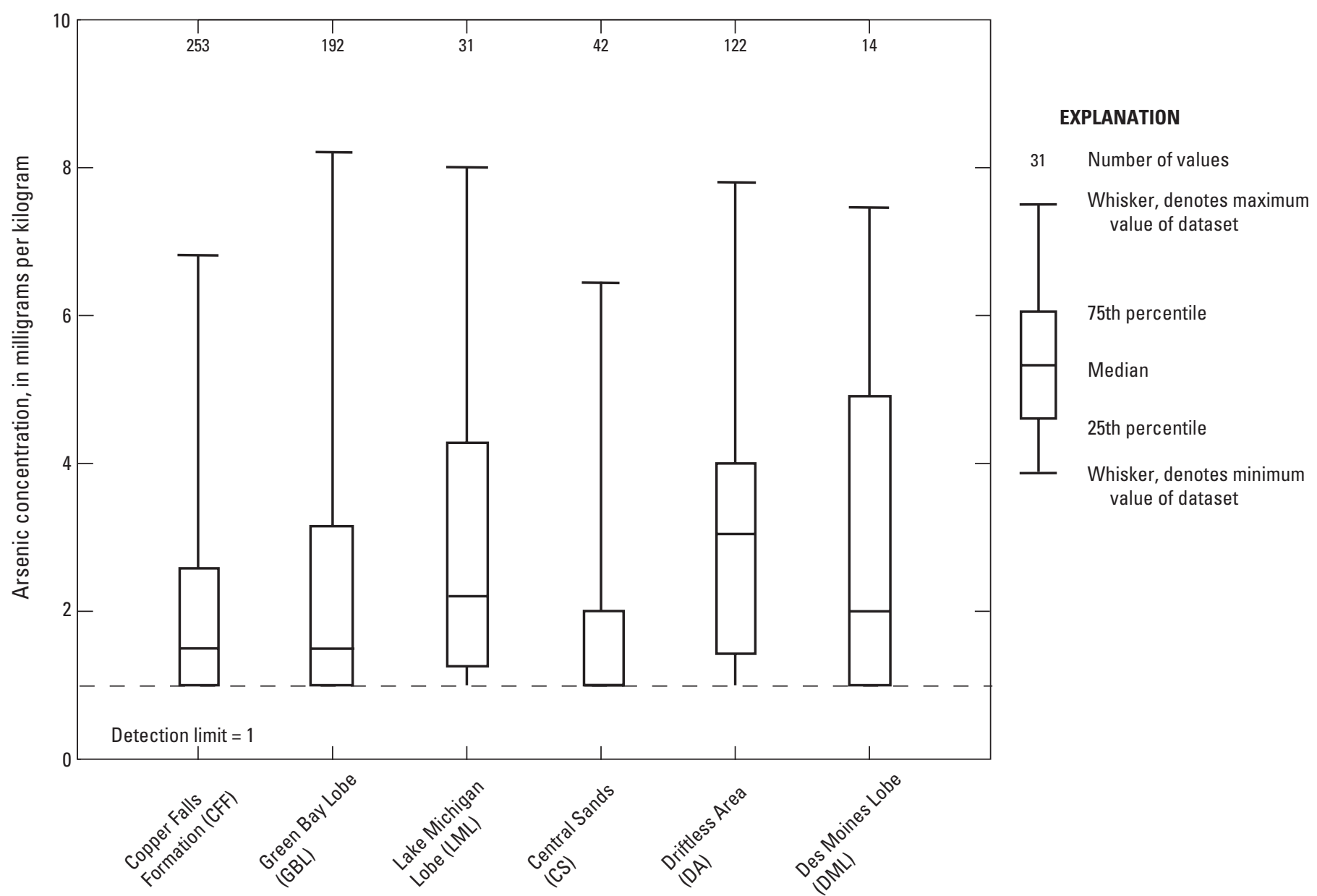

Figure 3. Statistical distribution of arsenic concentrations of surface soil samples in Wisconsin, categorized by the geographic regions shown in figure 1 and described in table 1, with outliers removed. 
dominate the region. Lake Michigan Lobe and Des Moines Lobe soils have similar median concentrations, $2 \mathrm{mg} / \mathrm{kg}$ and $2.2 \mathrm{mg} / \mathrm{kg}$, respectively, and Driftless Area soils have the highest median value at $3.0 \mathrm{mg} / \mathrm{kg}$ (table 4). The Des Moines Lobe range of values is larger than both the Lake Michigan Lobe and Driftless Area ranges of observed concentrations, which are similar (fig. 3).

Wilcoxon rank-sum test results were used to determine whether arsenic concentrations from the geographic regions were statistically different (table 5). Results generally support what is suggested by the spatial patterns in figure 2 and apparent in the boxplot of figure 3 . Arsenic concentrations in Central Sands soils were significantly different (probability (p) $<0.05$ ) from three of the other soil groups. Lake Michigan Lobe and Driftless Area soils have significantly different arsenic concentrations than Copper Falls Formation, Green Bay Lobe, and Central Sands soils. Des Moines Lobe soil arsenic concentrations are not significantly different from any geographic region, most likely because of the large range in observed values. On the basis of soil texture descriptions of the parent materials in the individual regions (table 1), it is probable that the presence of finer grained soils (higher clay content) in Lake Michigan Lobe, Driftless Area, and Des Moines Lobe accounts for the higher observed arsenic values. The dominance of sandy, coarse-textured soils in Central Sands accounts for the lowest concentrations of arsenic in the state. A combination of fine and coarse-grained soils in Copper Falls Formation and Green Bay Lobe results in arsenic concentrations intermediate to the other geographic region groupings.

\section{Comparison of Soil Arsenic Concentrations in Soil Groups}

The highest median concentration of arsenic in Wisconsin soils $(3.0 \mathrm{mg} / \mathrm{kg})$ is in somewhat poorly to excessively drained (WD) loess soils (fig. 4, table 4). Clay-rich soils have the next highest median arsenic with concentrations of 2.9 and $2.8 \mathrm{mg} /$ $\mathrm{kg}$, followed by poorly to very poorly drained (PD) loamy

Table 5. P-values from the Wilcoxon rank-sum test for comparing two sets of data on arsenic concentrations in Wisconsin surface soils.

[* indicates the two data sets are significantly different; $\mathrm{p}<0.05 ; \mathrm{PD}$, poor to very poor drainage; WD, somewhat poor to excessive drainage; CFF, Copper Falls Formation; GBL, Green Bay Lobe; LML, Lake Michigan Lobe; CS, Central Sands; DA, Driftless Area;

DML, Des Moines Lobe]

\begin{tabular}{|c|c|c|c|c|c|c|c|c|}
\hline & \multicolumn{8}{|c|}{ Soil group } \\
\hline & WD, Loess & PD, Sand & WD, Sand & PD, Clay & WD, Clay & PD, Loam & WD, Loam & Organic \\
\hline PD, Loess & 0.21 & 0.08 & $* 0.00$ & 0.62 & 0.54 & 0.30 & 0.35 & 0.30 \\
\hline WD, Loess & & $* 0.00$ & $* 0.00$ & 0.85 & 0.92 & 0.90 & $* 0.00$ & $* 0.00$ \\
\hline PD, Sand & & & 0.36 & $* 0.04$ & 0.66 & $* 0.00$ & 0.10 & 0.22 \\
\hline WD, Sand & & & & $* 0.00$ & $* 0.00$ & $* 0.00$ & $* 0.00$ & $* 0.00$ \\
\hline PD, Clay & & & & & 0.85 & 0.72 & 0.11 & 0.13 \\
\hline WD, Clay & & & & & & 0.59 & 0.18 & 0.15 \\
\hline PD, Loam & & & & & & & $* 0.01$ & $* 0.01$ \\
\hline \multirow[t]{3}{*}{ WD, Loam } & & & & & & & & 0.69 \\
\hline & \multicolumn{5}{|c|}{ Geographic region } & & & \\
\hline & GBL & LML & CS & DA & DML & & & \\
\hline $\mathrm{CFF}$ & 0.92 & $* 0.00$ & $* 0.03$ & $* 0.00$ & 0.55 & & & \\
\hline GBL & & $* 0.00$ & 0.12 & $* 0.00$ & 0.50 & & & \\
\hline LML & & & $* 0.00$ & 0.92 & 0.32 & & & \\
\hline CS & & & & $* 0.00$ & 0.28 & & & \\
\hline DA & & & & & 0.52 & & & \\
\hline
\end{tabular}


soils with a median arsenic concentration of $2.6 \mathrm{mg} / \mathrm{kg}$. PD loess soils have a lower median arsenic concentration than WD loess soils, but PD loamy soils have a higher median arsenic concentration than WD loamy soils. Sandy soils have a small range of low concentrations and median arsenic values below the $1-\mathrm{mg} / \mathrm{kg}$ detection limit. Organic soils have a median arsenic concentration of $1.6 \mathrm{mg} / \mathrm{kg}$. It is apparent from this dataset that soil properties can have a significant influence on soil arsenic concentrations.

The Wilcoxon rank-sum test results for the soil groups (table 5) corroborate what is evident in figure 4. WD sandy soils, which are typical for the CS, have significantly different arsenic concentrations than all other soil groups except PD sandy soils (table 5). PD loams and WD loams also have significantly different arsenic concentrations from one another, as apparent in figure 4. Drainage category accounts for the differences in arsenic concentrations in that situation.

\section{Data on Other Trace Elements}

In addition to arsenic, 16 other trace elements were analyzed in the soil samples collected. The geochemical data are presented herein, but in-depth discussion of the data for the remaining 16 trace elements is beyond the scope of this report. The data from these elements were treated similarly as the arsenic data described herein, and statistical characteristics were calculated with the same approach. However, the statistical analysis of the remaining trace elements did not consider the relationship to soil properties or geographic areas. Preliminary maps and histograms are in the appendix (figs. 1-2 through 1-17). In the case of the trace element molybdenum, there were too many non-detect values (91 percent; appendix, table 1-2) to calculate the summary statistics by using the available censored-data techniques. The raw data for all 17 trace elements sampled and analyzed for in this study are available in appendix table 1-1, and summary statistics are in appendix table $1-2$.

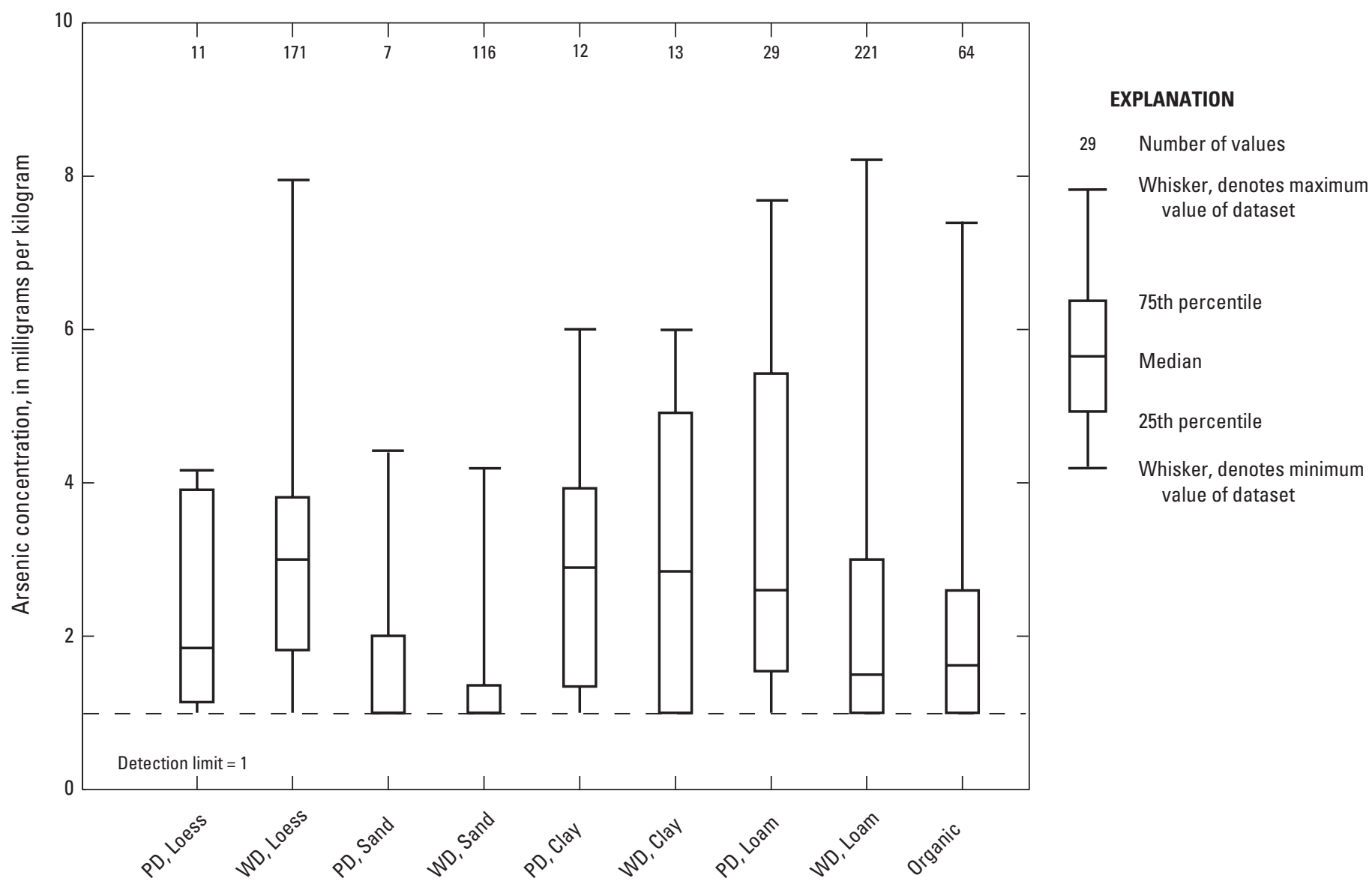

Figure 4. Statistical distribution of arsenic concentrations of surface soil samples in Wisconsin, categorized by soil characteristic group described in table 2 , with outliers removed. (PD, poorly drained; WD, well drained) 


\section{Summary and Conclusions}

Arsenic data from 664 surface soil samples taken across the state of Wisconsin were statistically analyzed to characterize baseline concentrations and determine if variations in these baseline concentrations exist as a result of physical and chemical soil properties or parent materials. In general, arsenic concentrations in Wisconsin surface soils with minimal anthropogenic influence are low. For the 654 samples collected for this study (excluding the 10 outliers), soil arsenic concentrations ranged from less than 1 to $8.3 \mathrm{mg} / \mathrm{kg}$, with median, mean, and the 95-percent upper confidence limit for the mean at $1.8,2.3$, and $2.4 \mathrm{mg} / \mathrm{kg}$, respectively. These data underscore the narrow distribution of background soil arsenic concentrations in Wisconsin surface soils. Higher-order statistical analysis yielded 90th-, 95th-, and 99th-percentile concentrations of $4.3,5.6$, and $7.4 \mathrm{mg} / \mathrm{kg}$, respectively. Sandy glacial outwash soils, common in the central part of the State, have significantly lower arsenic concentrations than soils formed in most of the other parent materials represented in this report. Soil texture of the upper 6 in. of the soil profile also influenced the arsenic concentration, with finer grained soils typically having the highest observed range of concentrations. Drainage category did not show a distinct relation to median concentration in comparison of similar soil textures. Arsenic concentrations of surface soils in Wisconsin appear to be influenced more by parent material and soil texture than by drainage category.

\section{References Cited}

Bradford, G.F., Change, A.C., Page, A.L., Bakhtar, D., Frampton, J.A., and Wright, H., 1996, Background concentrations of trace and major elements in California soils: University of California, Riverside, Kearny Foundation Special Report, $32 \mathrm{p}$.

Boerngen, J.G., and Shacklette, H.T., 1981, Chemical analyses of soils and other surficial materials of the conterminous United States: U.S. Geological Survey Open-File Report 81-197, 143 p.

Cannon, W.F, Woodruff, L.G, and Pimley, S., 2004, Some statistical relationships between stream sediment and soil geochemistry in northwestern Wisconsin-Can stream sediment compositions be used to predict compositions of soils in glaciated terranes?: Journal of Geochemical Exploration, v. 81, p. $29-46$.

Chen, M., Ma, L.Q., and Harris, W.G., 1999, Baseline concentrations of 15 trace elements in Florida surface soils: Journal of Environmental Quality, v. 28, p. 1173-1181.

Chen, M., Ma L.Q., and Harris, W.G., 2002, Arsenic concentration in Florida surface soils-Influence of soil type and properties: Soil Science Society of America Journal, v. 66, p. 632-640.

Clayton, Lee, Attig, John, Mickelson, D.M., Johnson, M.D., and Syverson, K.M., 2006, Glaciation of Wisconsin [3d ed.]: Wisconsin Geological and Natural History Survey Educational Series 36, 4 p.

Das, D., Samanta, G., Mandal, B.K., Chowdhury, T.R., Chanda, C.R., Chowdhury P.P., Basu, G.K., and Chakraborti, D., 1996, Arsenic in groundwater in six districts of West Bengal, India: Environmental Geochemistry and Health, v. 18, p. 5-15.

Elkhatib, E.A., Bennett, O.L., and Wright, R.J., 1984, Arsenite sorption and desorption in soils: Soil Science Society of America Journal, v. 48, p. 1025-1030.

Frost, R.R., and Griffin, R.A., 1977, Effect of pH on adsorption of arsenic and selenium from landfill leachate by clay minerals: Soil Science Society of America Journal, v. 41, p. 53-57.

Girouard, E., and Zagury, G.J., 2009, Arsenic bioavailability in CCA-contaminated soils - Influence of soil properties, arsenic fractionation, and particle-size fraction: Science of the Total Environment, v. 407, p. 2576-2585.

Goldberg, S., and Glaubig R.A., 1988, Anion sorption on a calcareous, montmorillonitic soil-Arsenic: Soil Science Society of America Journal, v. 52, p. 1297-1300. 
Gough, L.P., 1993, Understanding our fragile environmentLessons from geochemical studies: U.S. Geological Survey Circular 1105, $34 \mathrm{p}$.

Grosz, A.E., Grossman, J.N., Garrett, R., Friske, P., Smith, D.B., Darnley, A.G., and Vowinkel, E., 2004, A preliminary geochemical map for arsenic in surficial materials of Canada and the United States: Applied Geochemistry, v.19, p. 257-260.

Hole, F.D., 1976, Soils of Wisconsin: Madison, Wis., University of Wisconsin Press, 223 p.

Illinois Environmental Protection Agency, 2007, Tiered approach to corrective action objectives, accessed March 7, 2011, at http://www.epa.state.il.us/land/taco/fact-sheet.html.

Information Systems Programs, Energy Resources Institute, 1985, A technical history of the NURE HSSR program: U.S. Department of Energy GJBX-2(85), 58 p.

Kabata-Pendias, Alina, and Pendias, Henryk, 2001, Trace elements in soils and plants: Boca Raton, Fla., CRC Press, $413 \mathrm{p}$.

Kentucky Energy and Environment Cabinet, 2004, Kentucky guidance for ambient background assessment, accessed March 7, 2011, at http://waste.ky.gov/SFB/Documents/ AmbientBackgroundAssessment.pdf.

Michigan Department of Environmental Quality, 2005, Michigan background soil survey 2005: $10 \mathrm{p}$.

Montana Department of Environmental Quality, 2005, Action level for arsenic in surface soil, accessed March 7, 2011, at http://deq.mt.gov/StateSuperfund/PDFs/ ArsenicPositionPaper.pdf.

O’Neill, P., 1995, Arsenic, in Alloway, B.J. ed., Heavy metals in soils (2d ed.): New York, Blackie, p. 105-121.

Sanders, P.F., 2003, Ambient levels of metals in New Jersey soils: New Jersey Department of Environmental Protection Research Project Summary, accessed June 27, 2011, at http://www.state.nj.us/dep/dsr/research/ambient-levelsmetal.pdf.

Shacklette, H.T., and Boerngen, J.G., 1984, Element concentrations in soils and other surficial materials of the conterminous United States: U.S. Geological Survey Professional Paper 1270, $105 \mathrm{p}$.

Singh, Anita, Maichle, Robert, and Lee, S.E., 2006, On the computation of a $95 \%$ upper confidence limit of the unknown population mean based upon data sets with below detection limit observations: U.S. Environmental Protection Agency, EPA/600/R-06/022, 123 p.
Smith, A.H., Lingas, E.O., and Rahman, M., 2000, Contamination of drinking water by arsenic in Bangladesh-A health emergency: Bulletin of the World Health Organization, v. 78, p. 1096-1103.

Smith, E., Naidu, R., and Alston, A.M., 1998, Arsenic in the soil environment-A review: Advances in Agronomy, v. 64, p.149-195.

Smith, S.M., 1997, National Geochemical Database-Reformatted data from the National Uranium Resource Evaluation (NURE) Hydrogeochemical and Stream Sediment Reconnaissance (HSSR) Program: U.S. Geological Survey Open-File Report 97-492, version 1.40, accessed March 10, 2011, at http://pubs.usgs.gov/of/1997/ofr-97-0492/index. html.

U.S. Department of Agriculture, Soil Survey Division Staff, 1993, Soil survey manual: Soil Conservation Service, U.S. Department of Agriculture Handbook 18, 503 p.

Southworth, R.M., 1995, The Part 503 land application pollutant limits for arsenic: Washington, D.C., U.S. Environmental Protection Agency, [22] p.

Syverson, K.M., and Colgan, P.M., 2004, The Quaternary of Wisconsin-A review of stratigraphy and glaciation history, in Ehlers, J., and Gibbard, P.L., eds., Quaternary glaciations - Extent and chronology, Part II, North America: Amsterdam, Elsevier Publishing, p. 295-311.

Thanabalasingam, P., and Pickering, W.F., 1986, Arsenic sorption by humic acids: Environmental Pollution (Series B), v. 12 , p. 233-246.

U.S. Department of Agriculture, Natural Resources Conservation Service, 2006, Land resource regions and major land resource areas of the United States, the Caribbean, and the Pacific Basin (3d ed.): U.S. Department of Agriculture Handbook 296, 682 p.

U.S. Environmental Protection Agency, 1994, Method 200.7Methods for determination of metals in environmental samples, supplement 1: Washington, D.C., EPA 600/R94/111, $260 \mathrm{p}$.

U.S. Environmental Protection Agency, 2010, ProUCL Version 4.00.05 technical guide (draft): EPA 600/R-07/041, 236 p.

U.S. Geological Survey, 2004, The National Geochemical Survey—Database and documentation: U.S. Geological Survey Open-File Report 2004-1001, version 5.0, accessed March 10, 2011, at http://tin.er.usgs.gov/geochem/.

Vosnakis, K.A.S., Perry, E., Madsen, K., and Bradley, L.J.N., 2009, Background versus risk-based screening levels-An examination of arsenic background soil concentrations in seven states: Proceedings of the Annual International Conference on Soils, Sediments, Water, and Energy, v. 14, article 10. 
Appendix 1 


\section{Arsenic Soil Sampling Project - Field Procedure Work Plan April 17, 2007}

\section{Project Summary / Objectives}

Initial sampling of 38 sites was completed in the fall of 2006. Results and lessons learned from the pilot project have guided development of this plan for the rest of the project. An estimated 650 total sites will be sampled.

The end product will be a statistically verified range in Arsenic content for the top 6 inches of soil for each of the 9 soil groups identified below in each geographic area. Other potential soil groupings will also be explored, after the data is obtained and analyzed. Statistical analysis of the results will guide combinations of groups and geographic areas for practical presentation and use of the results.

After statistical analysis establishes significant soil groupings, a key, or chart, that identifies the properties used to place soils in each "Background Arsenic Content" (BAC) group will be developed. All soils in Wisconsin will be placed in one of the groups, and the data will be released in the form of an Excel spreadsheet or flat ASCII file. The possibility of posting BAC levels for every Wisconsin soil on Web Soil Survey (http://websoilsurvey.nrcs.usda.gov/app/) will be considered as the project proceeds.

In practical application, users will be able to utilize the BAC data by one of 2 methods:

1) If analysis of the data provides technical support for significant aggregation of soils based on general soil patterns or geographic regions such as MLRAs, a statewide BAC map will be created at a scale of about 1:750,000 or smaller. A responsible party can then use this map to identify the regional BAC for a specific contaminated site.

If anaylsis of the data does not support aggregation, a responsible party will identify the BAC for each soil mapped on a contaminated site, using the official USDA, NRCS detailed $(1: 12,000)$ soil survey maps. Then, using rules developed by DNR, the responsible party will determine the remediation level required.

2) In many cases, a responsible party will create a map of the contaminated site as part of the site investigation which includes a determinination of soil properties by a qualified site investigator. The investigator will identify the study group most closely representing the soil properties of the contaminated site, and use the BAC for that study group to determine the appropriate site specific concentration and the need for remediation.

Note: In certain cases, a responsible party may still choose to sample and test for As content to establish site specific BAC levels. In these cases, the BAC levels determined by this study will not be used.

Figure 1-1. Facsimile of draft field procedure work plan for Wisconsin arsenic sampling project. 


\section{Field activities \& data development}

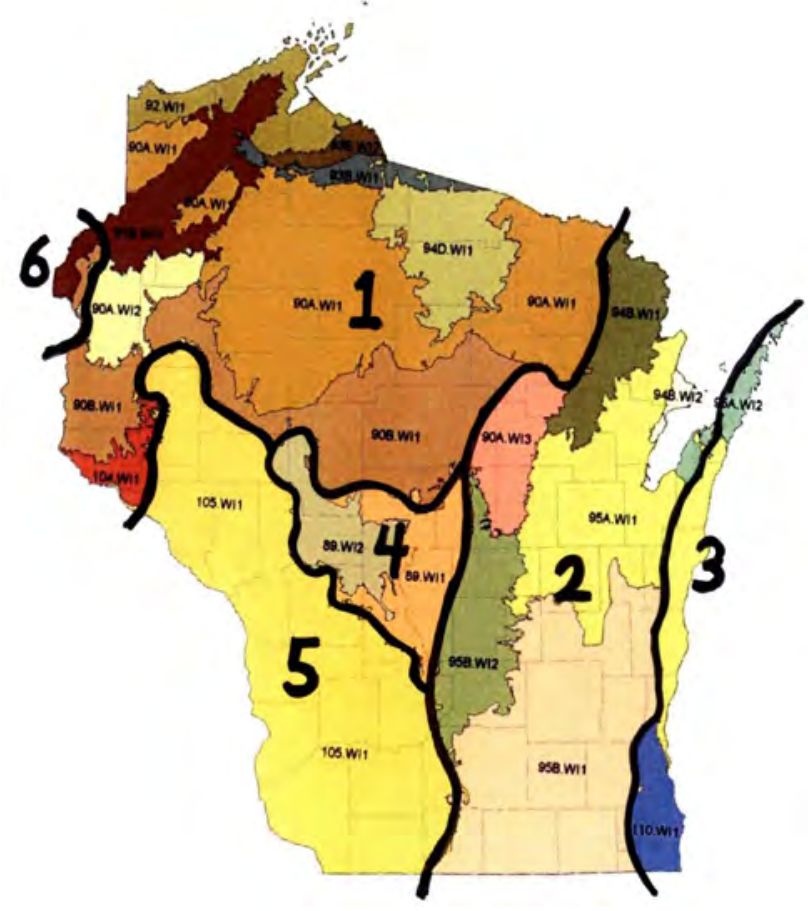

Step 1: Identify the soil series occurring in each of the following geographic areas. These areas represent the major surficial parent material sources in Wisconsin:

1) Copper Falls Formation

2) Green Bay Lobe

3) Lake Michigan Lobe

4) Central Sands

5) Driftless area

6) Des Moines Lobe

Note: There are other potential divisions, For example, MLRAs $90 B$ and 104 include mostly older tills, not within the Copper Falls Fm. The south part of 95B along the Illinois border also includes mostly older tills, and the east part of 95B, the rolling Kettle-Moraine area of Wisconsin, includes materials from the Lake Michigan Lobe.

Although the ages of materials in these areas vary, most soils are influenced by the more recent deposition of loess. It is estimated that the source areas and composition of the surficial soil materials in these "sub-areas" are similar, for the purposes of this study, to the larger region they are included in.

Area number 6, although small, is separated out because the source material is calcareous Des Moines Lobe till deposited from the SW, and is considerably different in properties which may affect Arsenic content from the adjacent Superior Lobe till, deposited from the NE.

Step 2: Within each geographic area, assign each soil to one of the following nine groups, based on surface soil parent material, surface soil texture, and drainage:

\section{Loess or loess-derived silts}

1) $P$ and VP drainage

2) $S P$ to $E$ drainage

Figure 1-1. Facsimile of draft field procedure work plan for Wisconsin arsenic sampling project.—Continued 


\section{Other mineral parent materials}

$\underline{s \& \text { Is surface textures }}$

3) $P$ and VP drainage

4) $S P$ to $E$ drainage

sc, C, Cl, sicl, \& sic surface textures

5) $P$ and VP drainage

6) SP to $E$ drainage

si, sil, l, sl, \& scl surface textures

7) $P$ and VP drainage

8) SP to $E$ drainage

\section{Organics}

9) all

Step 3: Identify high-acreage indicator soils to represent all soils in each group. These soils will be targeted for sampling. In general, we will attempt to sample at least two soils for each group that occurs in each geographic area. The remaining samples will be chosen to provide a roughly proportional representation of the extent of the geographic area and each soil group in the area. For 650 samples, each sample represents about 84 square miles. The density of sampling in areas 3, 4, and 6 may be somewhat higher than in the other areas.

Notes: Within each group, we will attempt to ensure that all Suborders in the group are represented, and that the full extent of the geographic area is represented. We will attempt to sample at least 3 sites in every county.

It is anticipated that statistical analysis of the results may permit conclusions based on soil properties other than those used to identify the original soil groups. The statistician will also provide guidelines for determining when to disregard a sample with especially high Arsenic content.

Nine groups $\times 6$ areas $=54$ total soil groups to sample. If we collect 650 samples, this is an average of about 12 samples per group. However, the actual number of samples collected for any particular group will vary, because the number of samples should be roughly proportional to the extent of that group in the area. We anticipate that statistical analysis of the results will permit us to combine some geographic areas and soil groups, so that a larger sample size will ultimately be used to support results and conclusions.

\section{Field Equipment}

Auger, Munsell color book, Clinometer, Field data sheets, Aerial photography, Handheld or tablet GPS unit, Sample bags (SLOH), stainless steel spade, disposable gloves (incomplete list).

\section{Soil Classification Guidelines}

To achieve the purposes of this study, we must be able to correlate laboratory results for content of Arsenic and other contaminants from specific sampled pedons to similar soils throughout each geographic region.

Many older soil surveys in Wisconsin were completed using taxonomic concepts, series concepts, and mapping procedures that do not meet current standards. Map units commonly include, as dominant components, several similar soil series, not just the named series. For this reason, it is not reasonable or necessary to require that a sampled pedon match the series of the mapped major component(s).

Figure 1-1. Facsimile of draft field procedure work plan for Wisconsin arsenic sampling project.—Continued 
To ensure that we can draw scientifically valid conclusions, it is essential only that a sampled pedon represents a major component of the map unit, as it is mapped in the general area.

If the pedon meets both of the following criteria, proceed. If not, move to a different location on the map unit, or select a new site:

1) The sampled pedon must classify within the same "sampling group" (step 2, above) as a major component of the map unit.

2) The sampled pedon must, in the best professional judgement of the field soil scientists, be representative of the soil properties of a major component of the map unit.

For purposes of this determination, soil scientists should consider soil properties of the components of the map unit, not just for the individual map unit sampled, but for the entire range of soil properties within all delineations of the map unit throughout its extent as originally mapped and correlated. It is recognized that soil scientists will often have to make this judgement based on incomplete data or knowledge, and that this judgement, while imperfect, is the best judgement possible, given the current status of mapping and soil science knowledge.

A pedon should be considered "representative" if the pedon properties are similar to a documented or presumed dominant component of the map unit. As described above, dominant components should be estimated using the best available data and professional knowledge. They do not have to be named or correlated map unit components.

Similar, for purposes of this study, refers to properties that may influence content and retention of Arsenic and similar contaminants: such as texture, parent material, drainage, organic matter, and $\mathrm{pH}$. For purposes of determining similarity, only near-surface properties, or subsurface properties, such as restrictive layers, that influence near-surface properties, must be considered.

If the pedon sampled does not meet the concept of the same series as a major map unit component, make a note on the field sheet describing why it is judged that the sampled pedon is representative of a map unit component, as mapped in the survey area.

\section{Field Procedures}

Sample locations will not be pre-selected. Instead samplers will choose sampling sites following the site selection guidelines below.

- Sample on public lands where possible. Or, obtain landowner permission to sample following standard NRCS soil survey procedures. Provide an informational handout to landowners, as needed (see appendix).

- Complete a brief profile description and classify the soil to the series level. Observe to the depth necessary to classify to the series level (usually 80 "). If it is difficult or impossible to observe to the required depth, a shallower core is acceptable if:

1) The description and classification is still adequate to meet the purposes and intent of the "Soil Classification Guidelines" section above and, with reasonable assumptions or estimates, the pedon can be classified to the series level; OR

2) It is reasonable to estimate or project the properties of the lower part of the pedon to 80", (eg: stones prevent augering below 50", and the sampled pedon shows a calcareous, loamy till C horizon from 42-50", and the sample is from a soil and area where sampling, mapping, and road cut

Figure 1-1. Facsimile of draft field procedure work plan for Wisconsin arsenic sampling project.—Continued 
observations indicate a thick stony, calcareous, loamy till is the expected soil parent material). If properties are estimated or projected to 80", describe the properties on the field sheet, and note that they were not directly observed, but were projected.

- Record GPS coordinates for each sample site, using a handheld or tablet GPS unit. Datum: NAD83. Coordinate system: Lat-Long. Elevation data is not needed. Complete an NRCS data sheet, including site information and the profile description (see Appendix A). Assign standard NRCS sample numbers.

- Move a few inches from the sample hole, or otherwise ensure that the only tool that touches the sample is the stainless steel spade. Wearing laboratory-grade disposable gloves and using the stainless steel spade, collect a slice of the upper 6 inches of the soil, discard large coarse fragments and collect at least a 1.5 cup sample representative of the slice. If the surface is undisturbed, remove any undecomposed organic material (SPM (Oi or Oe) horizon), before collecting the sample. Put the sample in a laboratory grade sample bag. You do not need to mix the sample. Make sure the zip-loc top is closed, and expel excess air.

- Fold over the top of the bag to minimize the chance of moisture leaking out of the bag, and doublebag the sample in a second laboratory-grade sample bag.

- Write the sample number, in ink, on a $3 \times 5$ note card (heavy paper, less likely to disintegrate), and insert the note card in a small plastic zip-loc baggie. Then include this note card inside the second sample bag with the number visible from the outside. A tag is not needed. Include only the sample number inside the second bag. Do not include a copy of the Field Data Sheet. There should be no clues that permit the laboratory staff to distinguish between the regular samples and the blind duplicate samples.

- Wipe down and water rinse the sampling equipment between sample sites. Discard disposable gloves after every sample.

- Take pictures of the core and sample site if a camera and time is available. This is not required.

- Keep track of: 1) hours worked on the Arsenic project, 2) miles driven, and 3) days of per diem claimed. At the end of every pay period, populate these 3 figures in the shared spreadsheet Jesse maintains.

- At the end of each day, update samples obtained on the shared spreadsheet Jesse maintains.

\section{Blind Duplicate Procedures -}

- At 10 percent of the sites, collect a blind duplicate. These can be collected at random intervals. Assign a unique sample number. Note 2 numbers on a Field Data Sheet: "Blind Duplicate sample number: __ " and "This duplicate corresponds to sample number ". No other data is needed for a blind duplicate. The sample number will link the blind duplicate to the data for the corresponding main sample number.

- Ensure that both samples are essentially identical duplicates of each other, so that you would expect laboratory tests for As content, particle size, $\mathrm{pH}$, etc to be the same. You can do that by taking 2 immediately adjacent slices, or by carefully splitting one large slice, or by thoroughly mixing a larger sample in a sample bag with your gloved hand and then dividing the sample in two.

- Include only the blind duplicate sample number in the second bag, as described above. These samples will serve as QA/QC samples to check and evaluate laboratory procedures.

- Enter the blind duplicate sample number and the sample number of the main sample on the shared spreadsheet Jesse maintains.

Figure 1-1. Facsimile of draft field procedure work plan for Wisconsin arsenic sampling project.—Continued 


\section{Site Selection Guidelines}

- Sample in woodlots, permanent pasture, or other relatively undisturbed areas, at least 20 feet away from fencelines.

- Do not sample within 1 mile of any other Arsenic study sample site.

- Do not sample within 5 miles of any other sample from the same soil group.

- Do not sample within 100 feet of existing or known historical construction sites or disturbed areas, such as roads, dumps, pits, pipelines, or homesites.

- Do not sample within 300 feet of areas of suspected or known contamination, such as:

- areas listed by the DNR Bureau for Remediation and Redevelopment Tracking System

(BRRTS): http://botw.dnr.state.wi.us/botw/Welcome.do

- current or old orchards or fields used to grow vegetable crops

- cattle dipping sites

- wood preservative activities

- Poultry or swine manure spreading areas

- land spreading of sewage waste or paper mill sludge

- areas where grasshopper bait may have had historical use

Figure 1-1. Facsimile of draft field procedure work plan for Wisconsin arsenic sampling project.—Continued 


\section{Arsenic Sampling Project - Field Data Sheet (DRAFT 4-10-07 - Appendix A)}

Date: Time: Soil Scientist:

Site Location: County Twp Range Section

Field GPS (lat-long):

Air temp:

Slope (\%): Aspect (degrees): Soil moisture: Weather:

Map unit symbol and name:

Land use / vegetative cover:

Est distance (feet) to disturbed area:

Taxclass:

Geographic area number: (1-6) Soil group number: (1-9)

Sample number(s): Series:

Note major horizons and parent material breaks. Estimate percent sand and clay for the surface and a representative subsoil horizon and note in the "texture" column, eg: 15s, 22c. Circle the horizons sampled.

\begin{tabular}{|c|c|c|c|c|c|c|c|c|}
\hline Horizon & depths & color & texture & structure & redox & frags & $\begin{array}{l}\mathrm{CO} 31 \\
\mathrm{pH}\end{array}$ & $\begin{array}{l}\text { parent } \\
\text { material }\end{array}$ \\
\hline & & & & & & & & \\
\hline & & & & & & & & \\
\hline & & & & & & & & \\
\hline & & & & & & & & \\
\hline & & & & & & & & \\
\hline & & & & & & & & \\
\hline & & & & & & & & \\
\hline
\end{tabular}

NOTES:

Figure 1-1. Facsimile of draft field procedure work plan for Wisconsin arsenic sampling project.-Continued 


\begin{abstract}
April 17, 2007
Dear Landowner,

The Wisconsin Department of Health and Family Services and Wisconsin Department of Natural Resources are conducting a scientific study to determine natural background levels of certain trace elements in Wisconsin soils. Soil samples from over 600 relatively undisturbed sites will be evaluated to establish target levels for cleanup of known contaminated sites.

The purpose of this study is not to identify contaminated sites, but simply to provide supporting background data to guide cleanup of known contaminated sites. Samples are being collected from indicator soils throughout Wisconsin. Soil scientists auger 3 inch diameter holes by hand, take notes, record the location, and collect pint sized soil samples. They will check with each landowner by phone or in person before walking on the land, to obtain permission to sample the soils.

This is a cooperative effort, completed in partnership with the United States Geological Survey, the USDA Natural Resources Conservation Service, and the Wisconsin Geological and Natural History Survey.

Please contact one of the following persons familiar with this study, if you have any questions or concerns.

Thank you,
\end{abstract}

David Hall, USGS

608-821-3875

dwhall@usgs.gov
Ed Lynch, DNR 608-266-3084

edward.lynch@wisconsin.gov
Chuck Warzecha, DHFS

608-267-3732

warzecj@dhfs.state.wi.us

Figure 1-1. Facsimile of draft field procedure work plan for Wisconsin arsenic sampling project.—Continued 


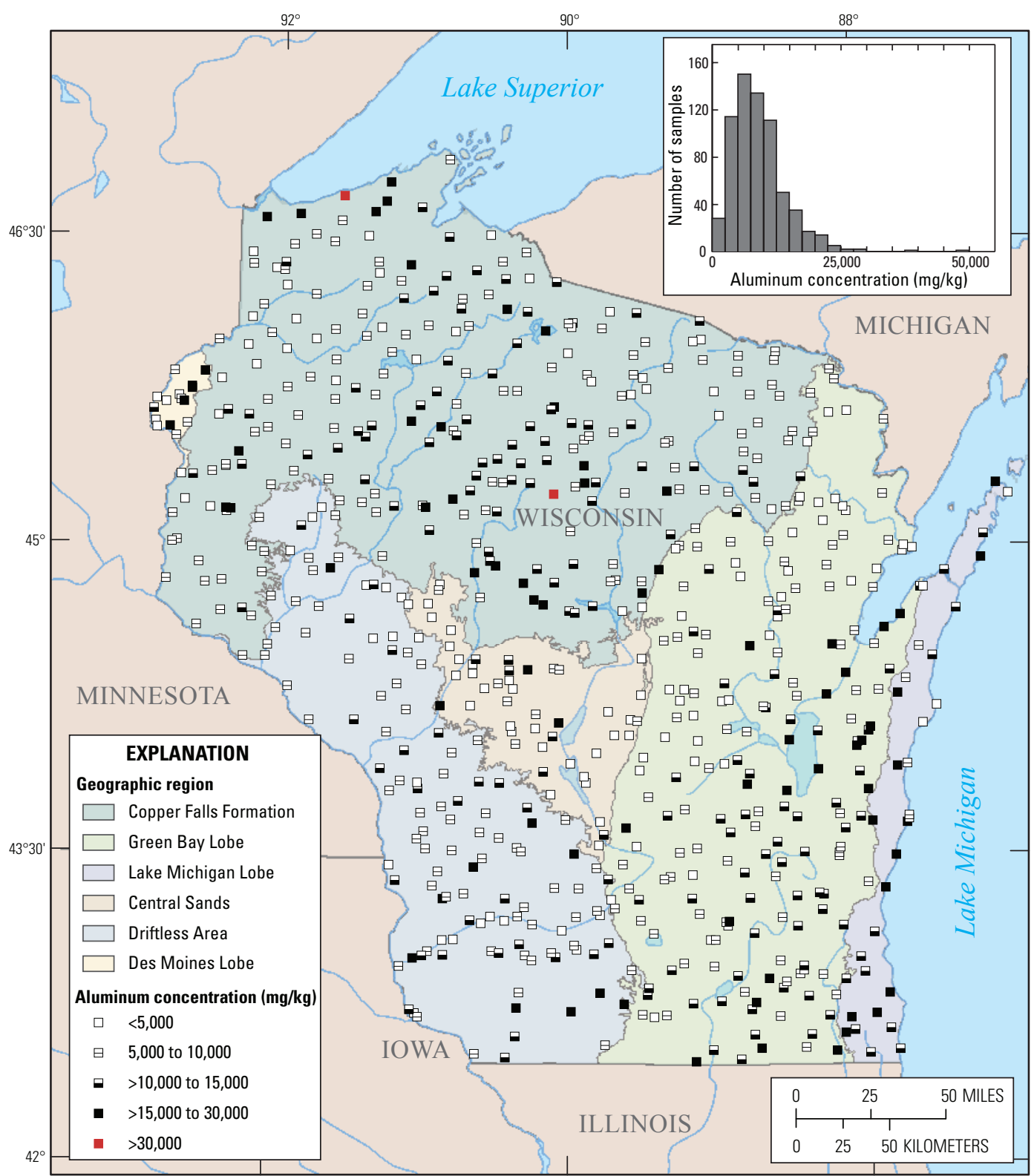

Figure 1-2. Spatial distribution of aluminum concentrations of surface soil samples in Wisconsin. The histogram in the figure gives the frequency distribution of the aluminum concentrations. The data displayed in both the map and the histogram include outliers that were removed prior to statistical analysis and are shown on the figure as red squares. 


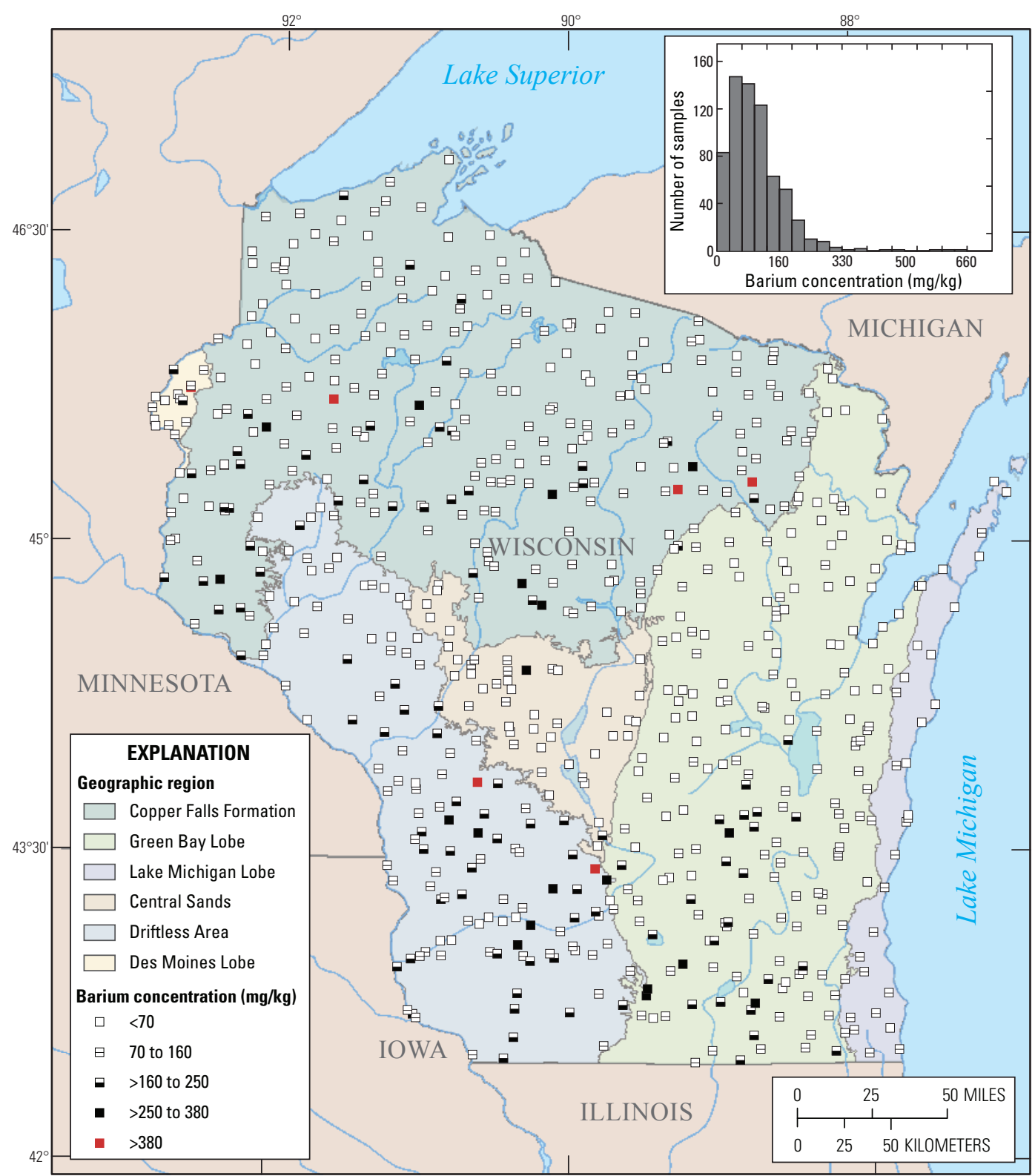

Figure 1-3. Spatial distribution of barium concentrations of surface soil samples in Wisconsin. The histogram in the figure gives the frequency distribution of the barium concentrations. The data displayed in both the map and the histogram include outliers that were removed prior to statistical analysis and are shown on the figure as red squares. 


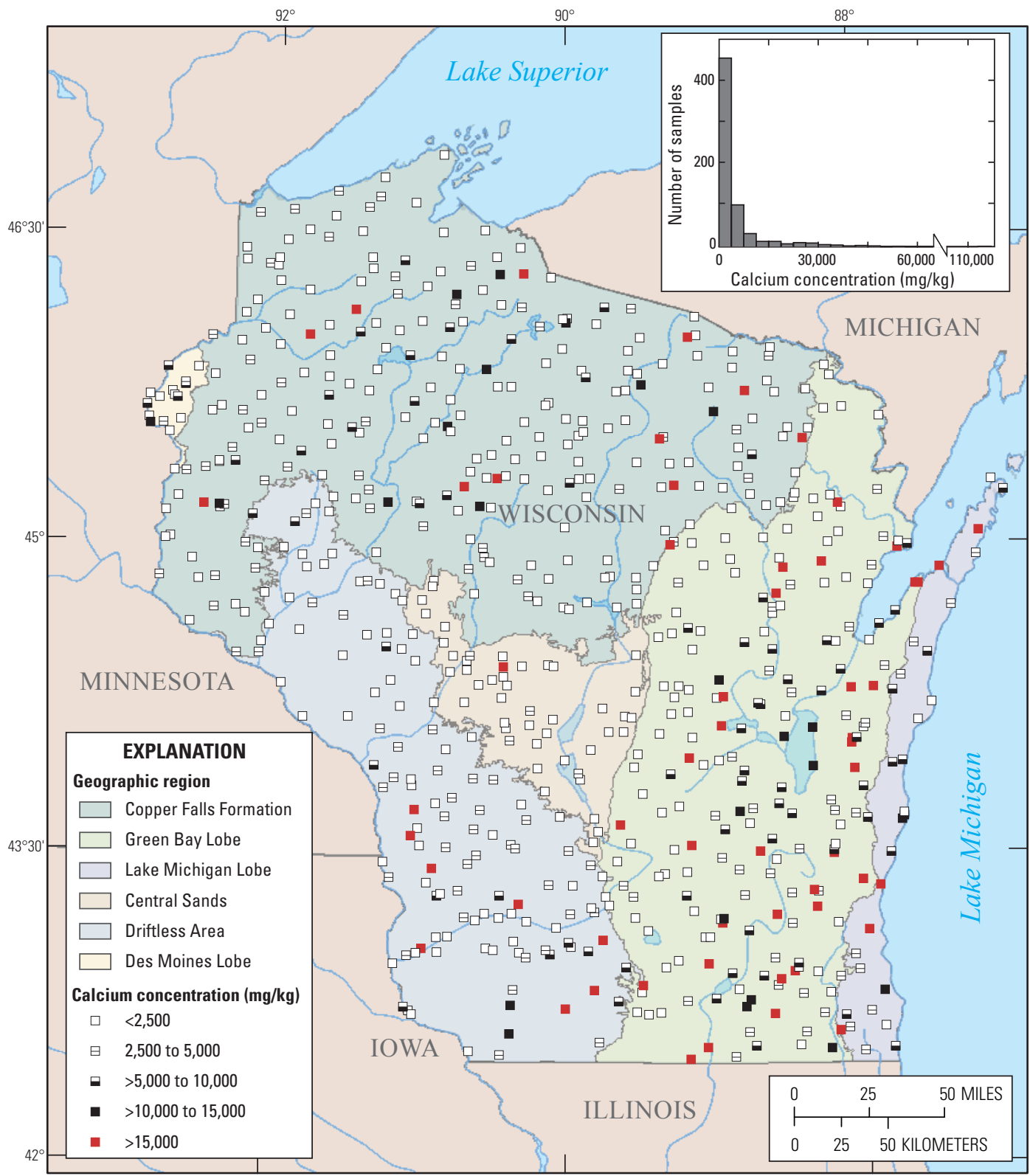

Figure 1-4. Spatial distribution of calcium concentrations of surface soil samples in Wisconsin. The histogram in the figure gives the frequency distribution of the calcium concentrations. The data displayed in both the map and the histogram include outliers that were removed prior to statistical analysis and are shown on the figure as red squares. 


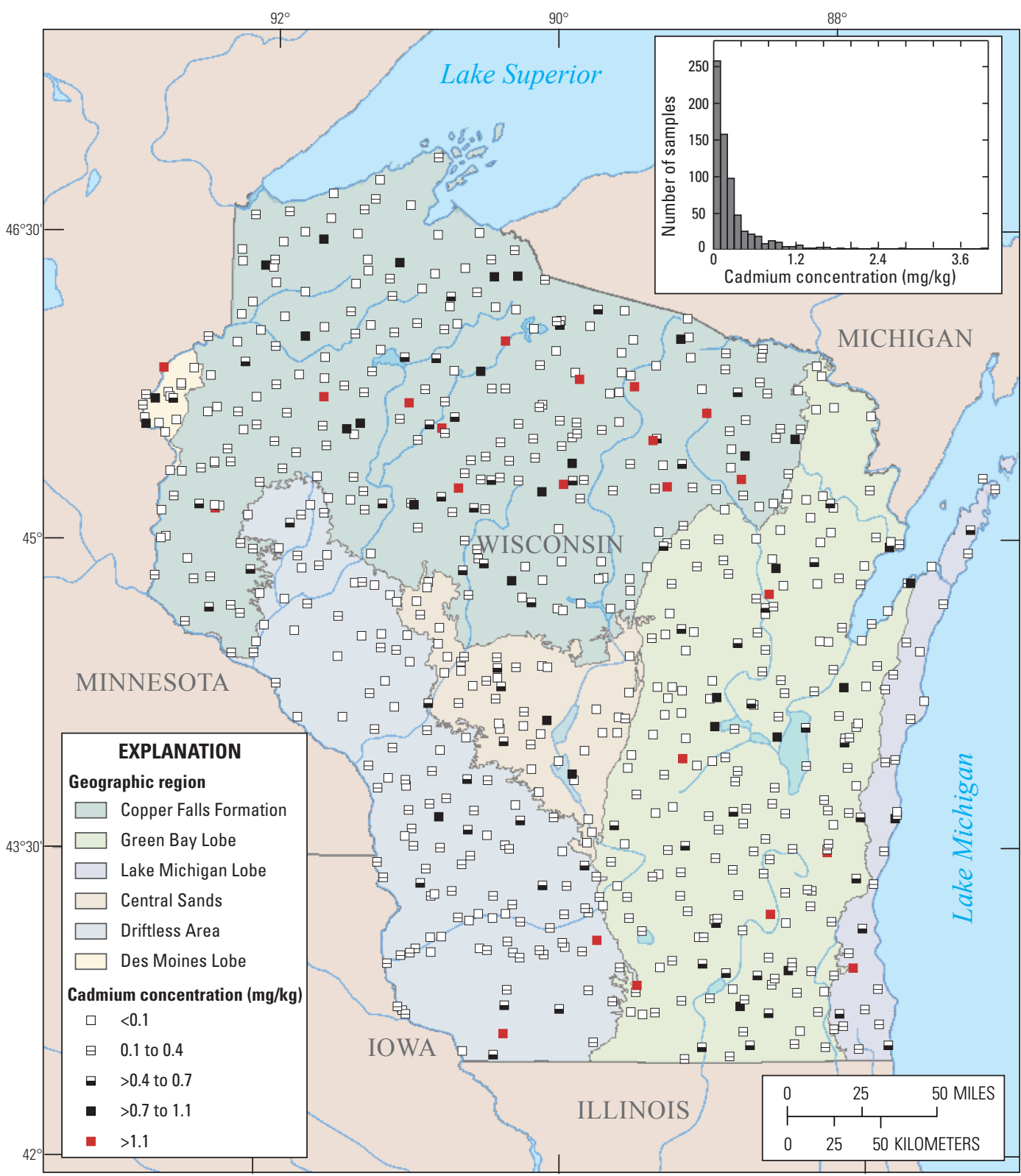

Figure 1-5. Spatial distribution of cadmium concentrations of surface soil samples in Wisconsin. The histogram in the figure gives the frequency distribution of the cadmium concentrations. The data displayed in both the map and the histogram include outliers that were removed prior to statistical analysis and are shown on the figure as red squares. 


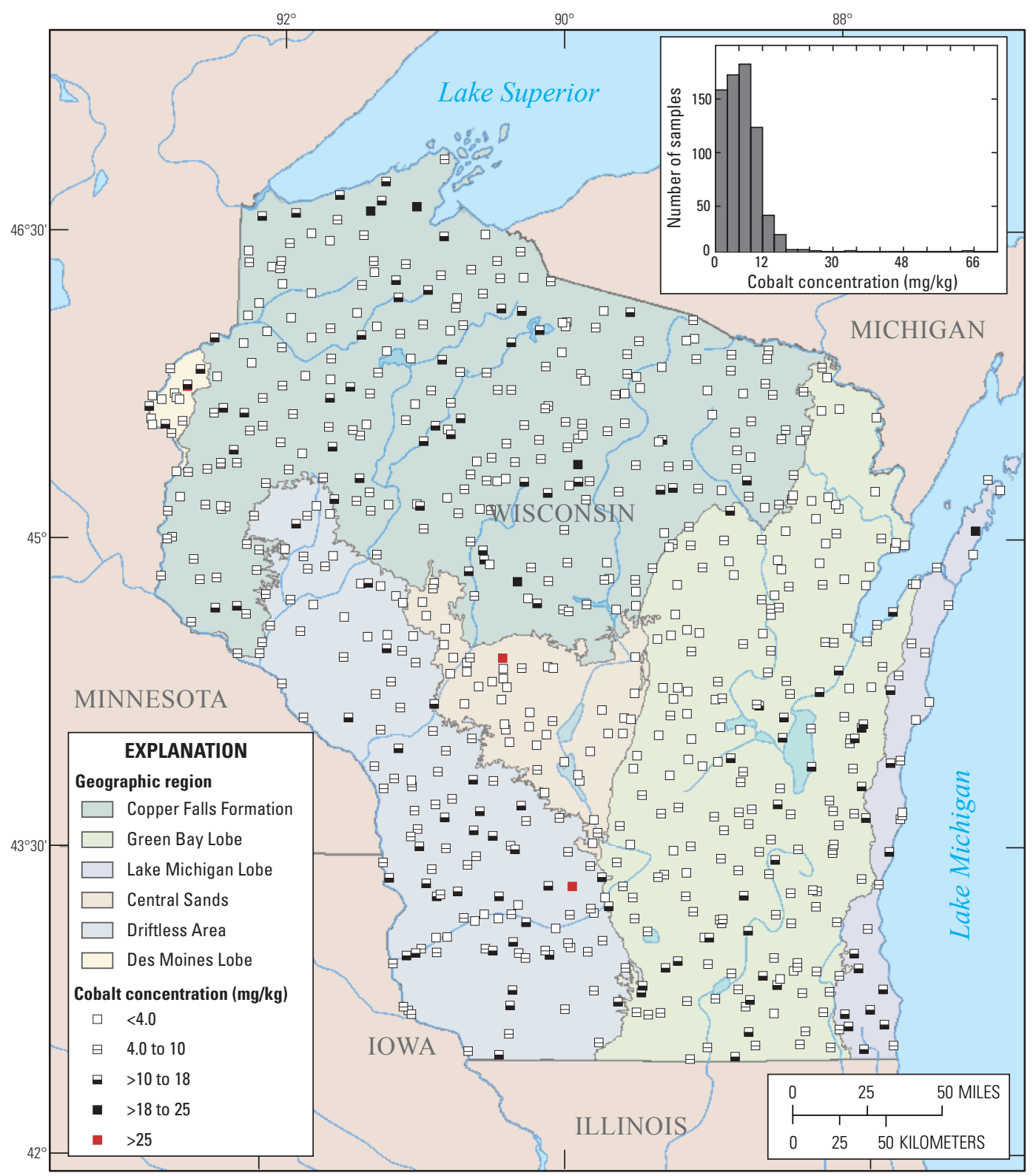

Figure 1-6. Spatial distribution of cobalt concentrations of surface soil samples in Wisconsin. The histogram in the figure gives the frequency distribution of the cobalt concentrations. The data displayed in both the map and the histogram include outliers that were removed prior to statistical analysis and are shown on the figure as red squares. 


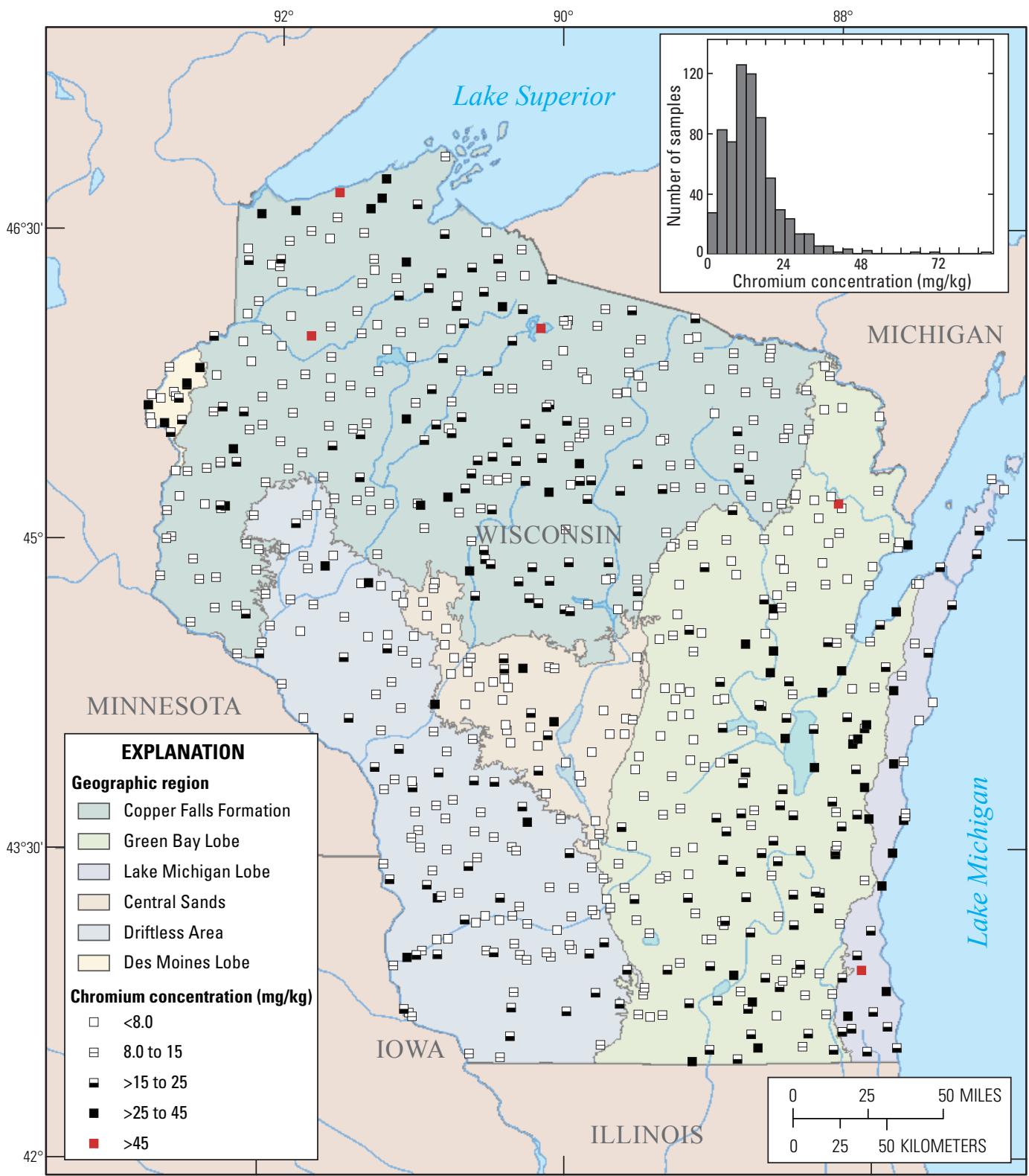

Figure 1-7. Spatial distribution of chromium concentrations of surface soil samples in Wisconsin. The histogram in the figure gives the frequency distribution of the chromium concentrations. The data displayed in both the map and the histogram include outliers that were removed prior to statistical analysis and are shown on the figure as red squares. 


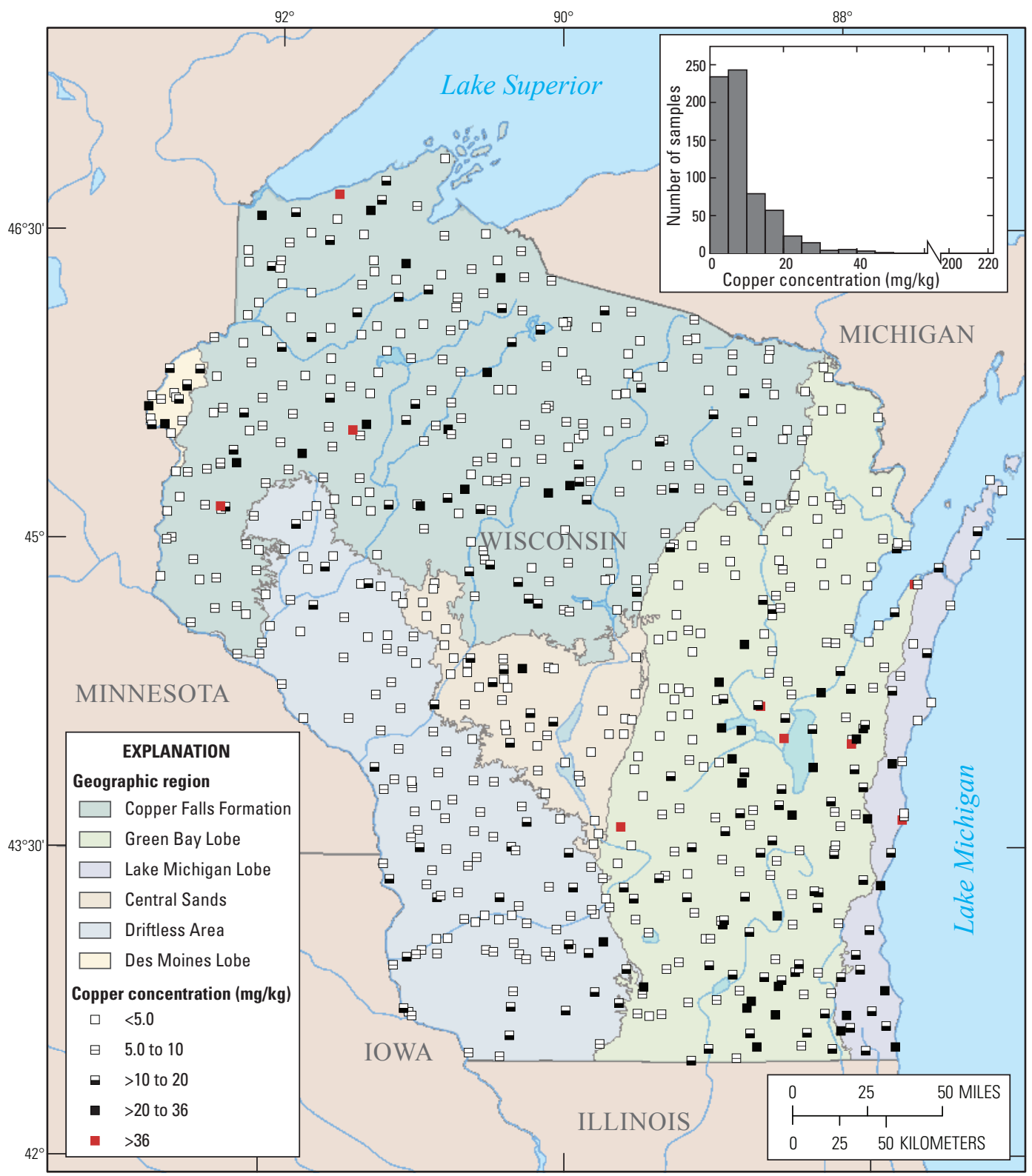

Figure 1-8. Spatial distribution of copper concentrations of surface soil samples in Wisconsin. The histogram in the figure gives the frequency distribution of the copper concentrations. The data displayed in both the map and the histogram include outliers that were removed prior to statistical analysis and are shown on the figure as red squares 


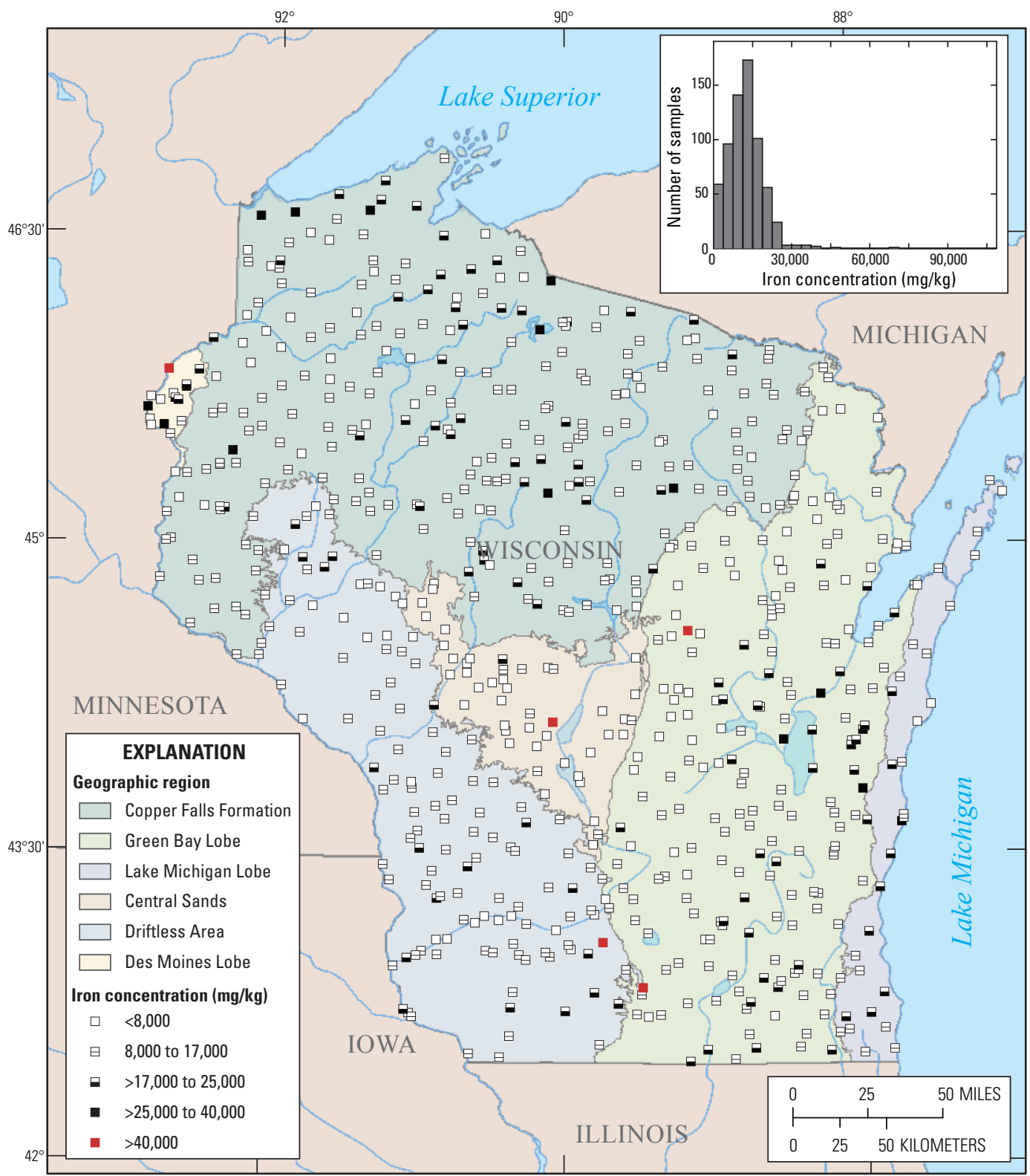

Figure 1-9. Spatial distribution of iron concentrations of surface soil samples in Wisconsin. The histogram in the figure gives the frequency distribution of the iron concentrations. The data displayed in both the map and the histogram include outliers that were removed prior to statistical analysis and are shown on the figure as red squares. 


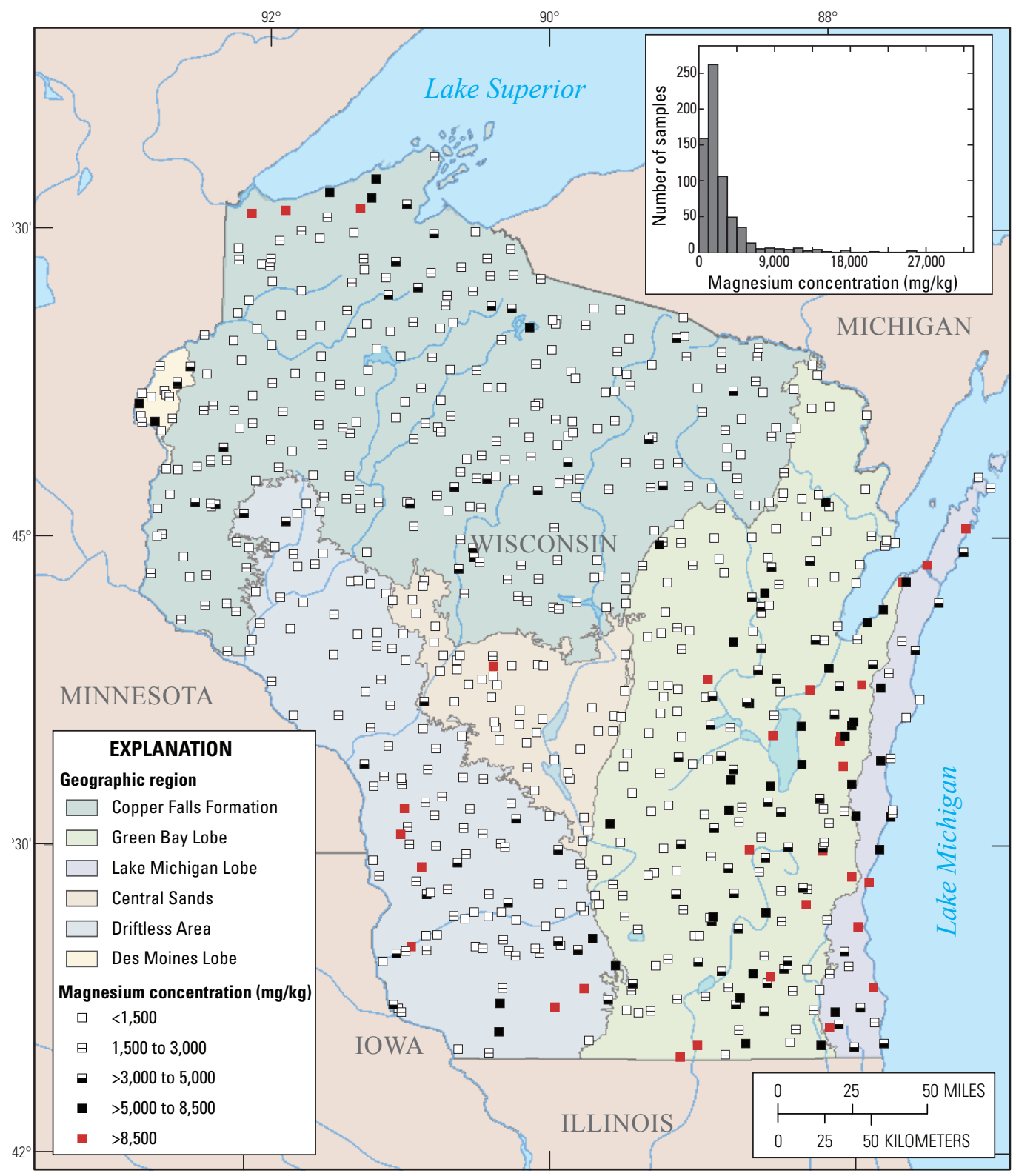

Figure 1-10. Spatial distribution of magnesium concentrations of surface soil samples in Wisconsin. The histogram in the figure gives the frequency distribution of the magnesium concentrations. The data displayed in both the map and the histogram include outliers that were removed prior to statistical analysis and are shown on the figure as red squares. 


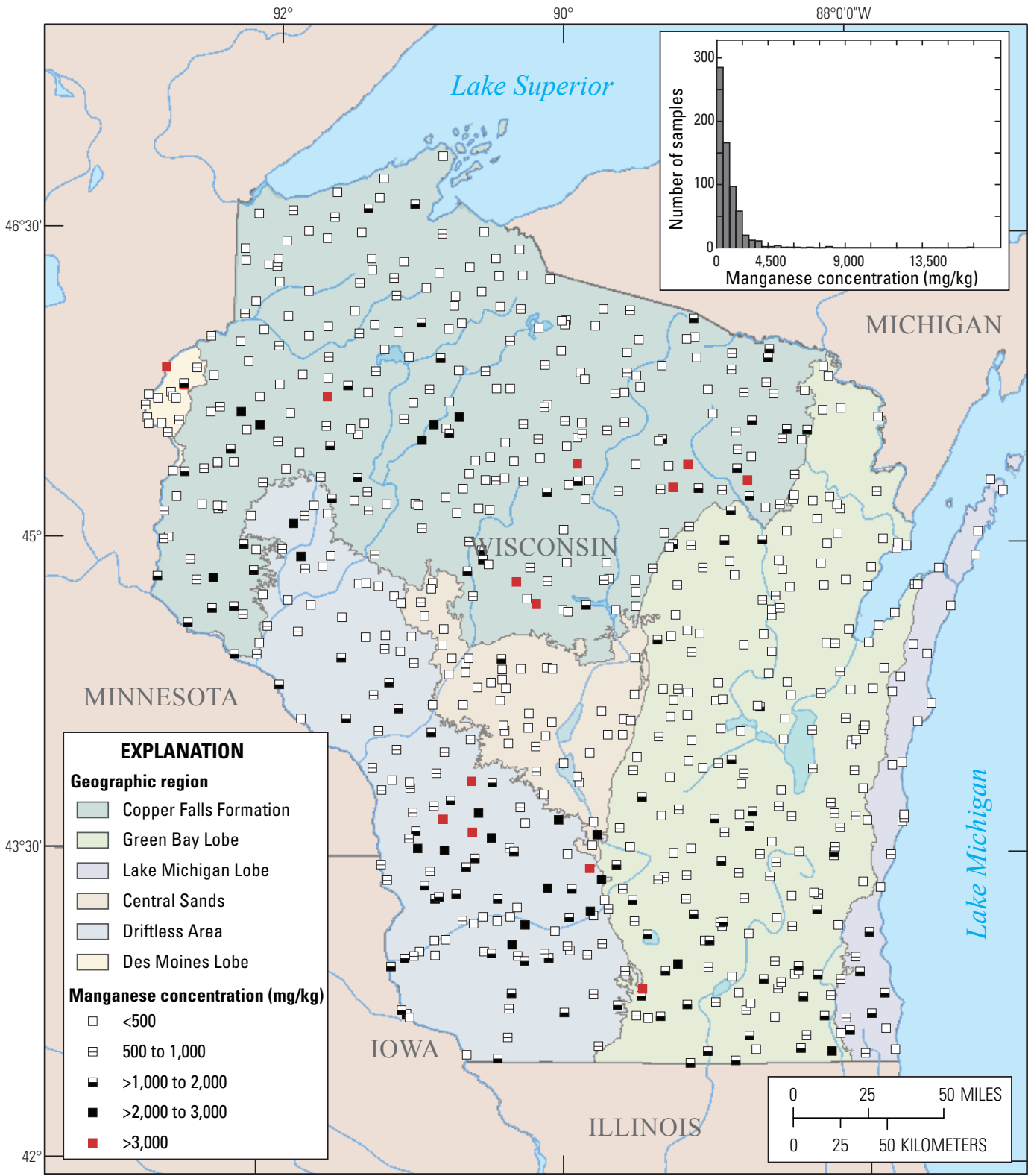

Figure 1-11. Spatial distribution of manganese concentrations of surface soil samples in Wisconsin. The histogram in the figure gives the frequency distribution of the manganese concentrations. The data displayed in both the map and the histogram include outliers that were removed prior to statistical analysis and are shown on the figure as red squares. 


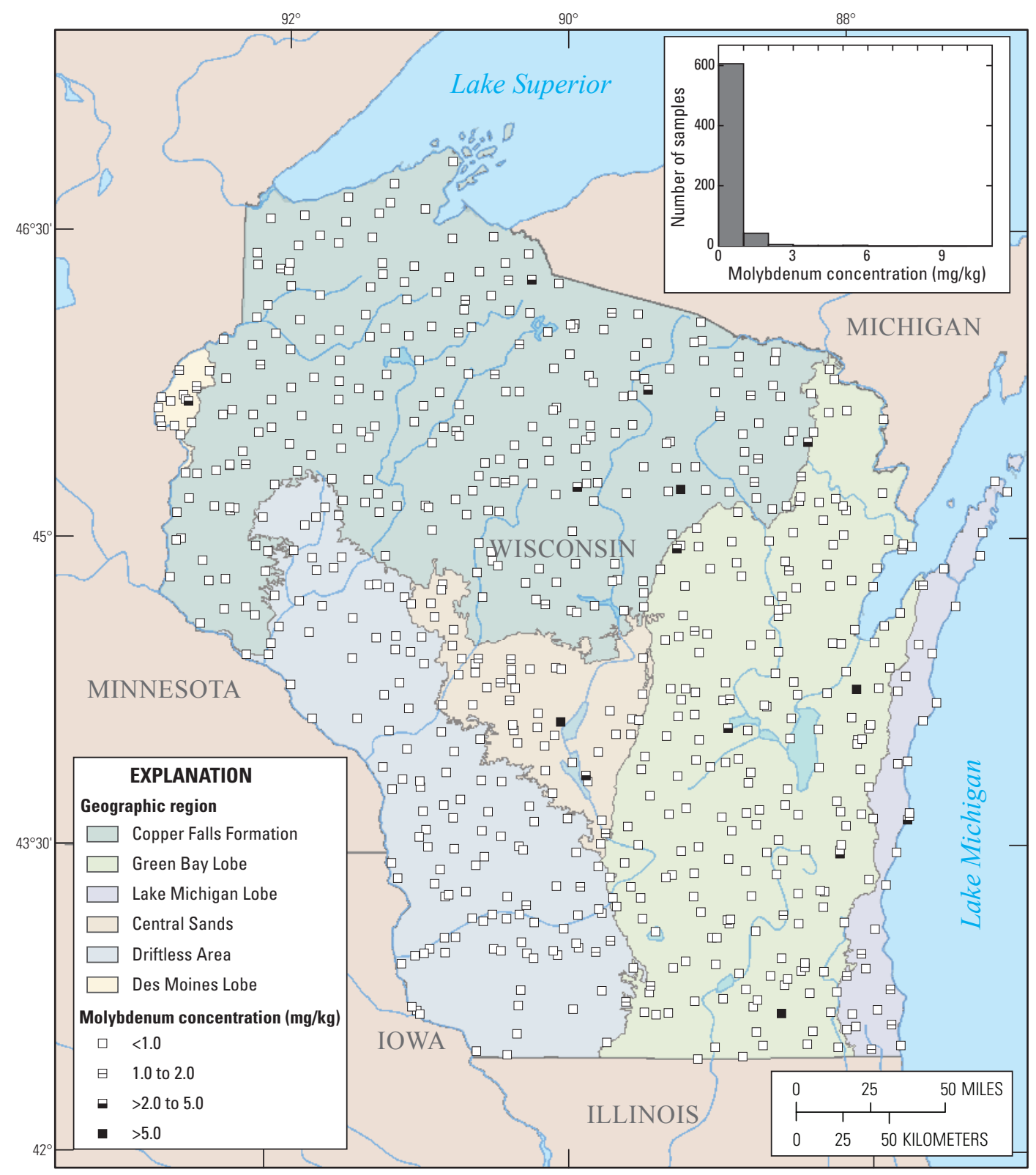

Figure 1-12. Spatial distribution of molybdenum (statistical analysis not done for this element) concentrations of surface soil samples in Wisconsin. The histogram in the figure gives the frequency distribution of the molybdenum concentrations. 


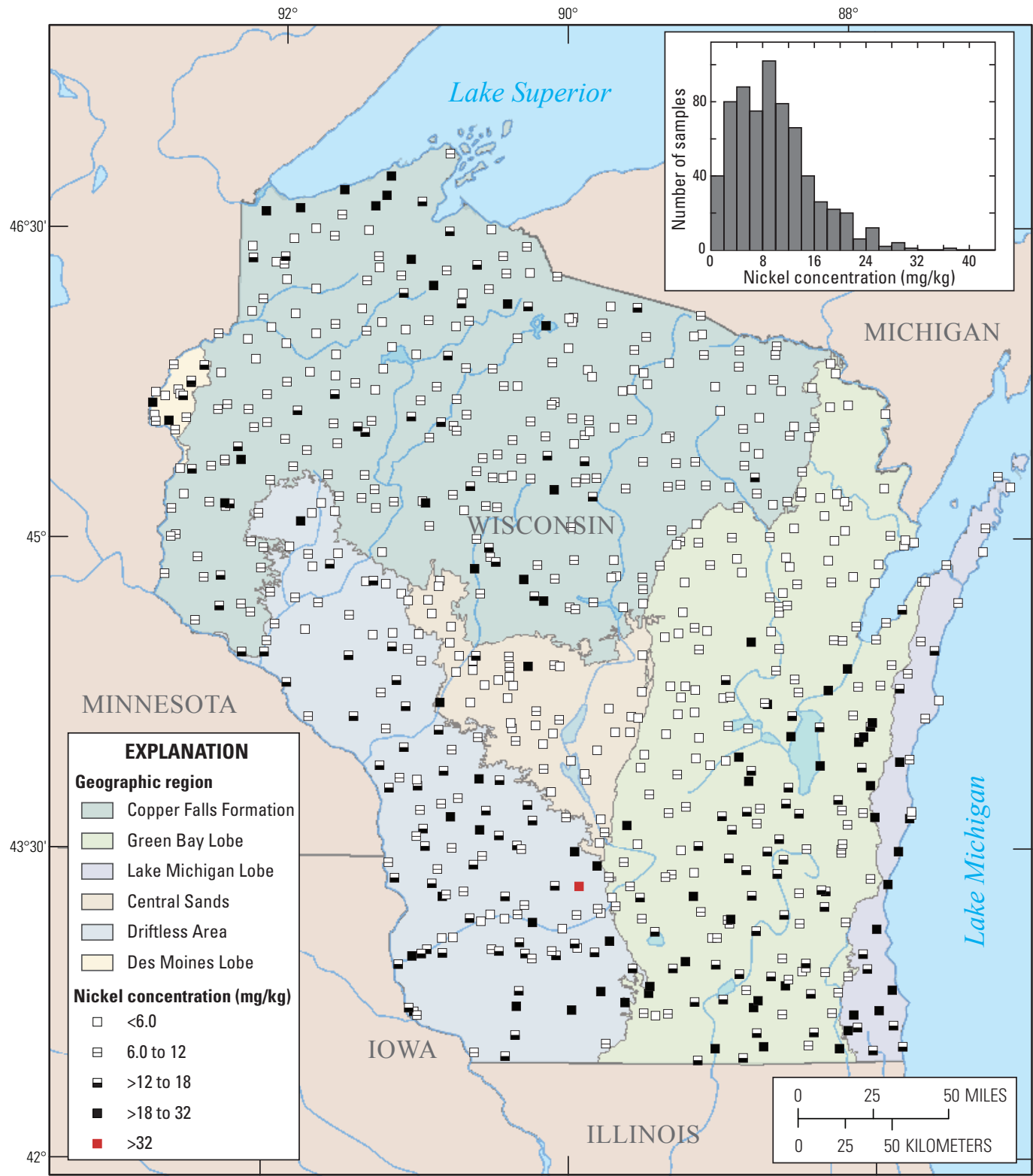

Figure 1-13. Spatial distribution of nickel concentrations of surface soil samples in Wisconsin. The histogram in the figure gives the frequency distribution of the nickel concentrations. The data displayed in both the map and the histogram include outliers that were removed prior to statistical analysis and are shown on the figure as red squares. 


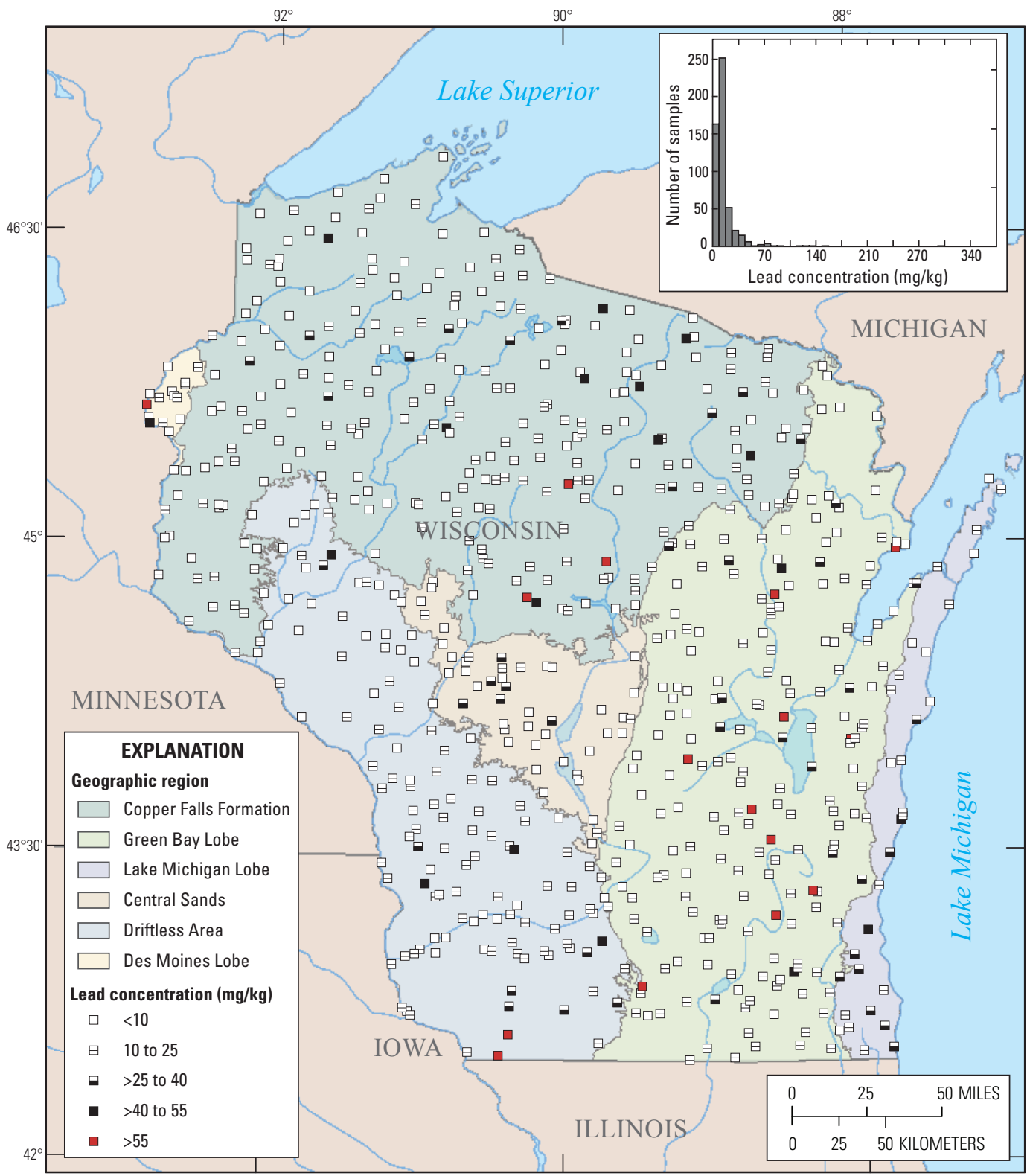

Figure 1-14. Spatial distribution of lead concentrations of surface soil samples in Wisconsin. The histogram in the figure gives the frequency distribution of the lead concentrations. The data displayed in both the map and the histogram include outliers that were removed prior to statistical analysis and are shown on the figure as red squares. 


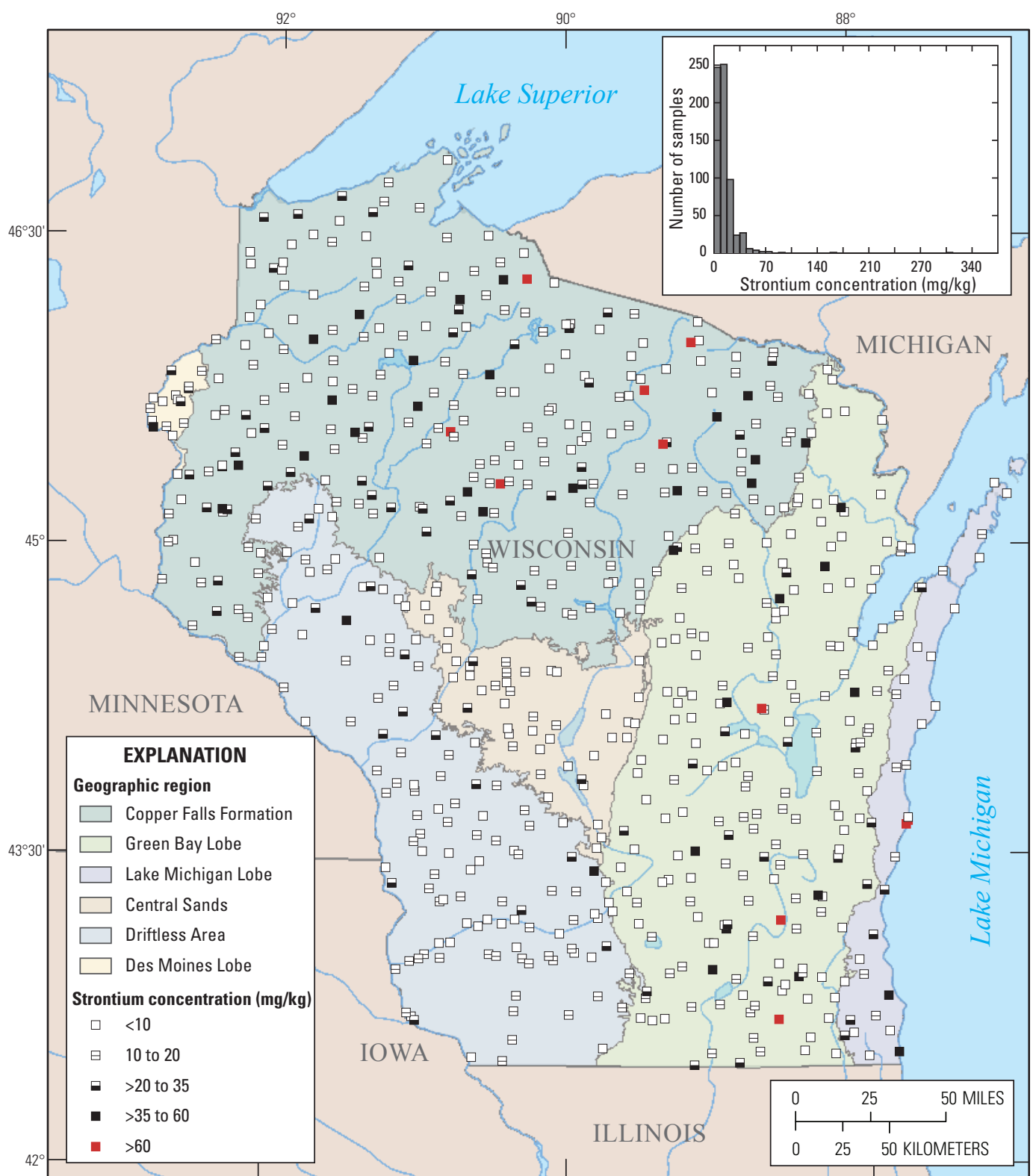

Figure 1-15. Spatial distribution of strontium concentrations of surface soil samples in Wisconsin. The histogram in the figure gives the frequency distribution of the strontium concentrations. The data displayed in both the map and the histogram include outliers that were removed prior to statistical analysis and are shown on the figure as red squares. 


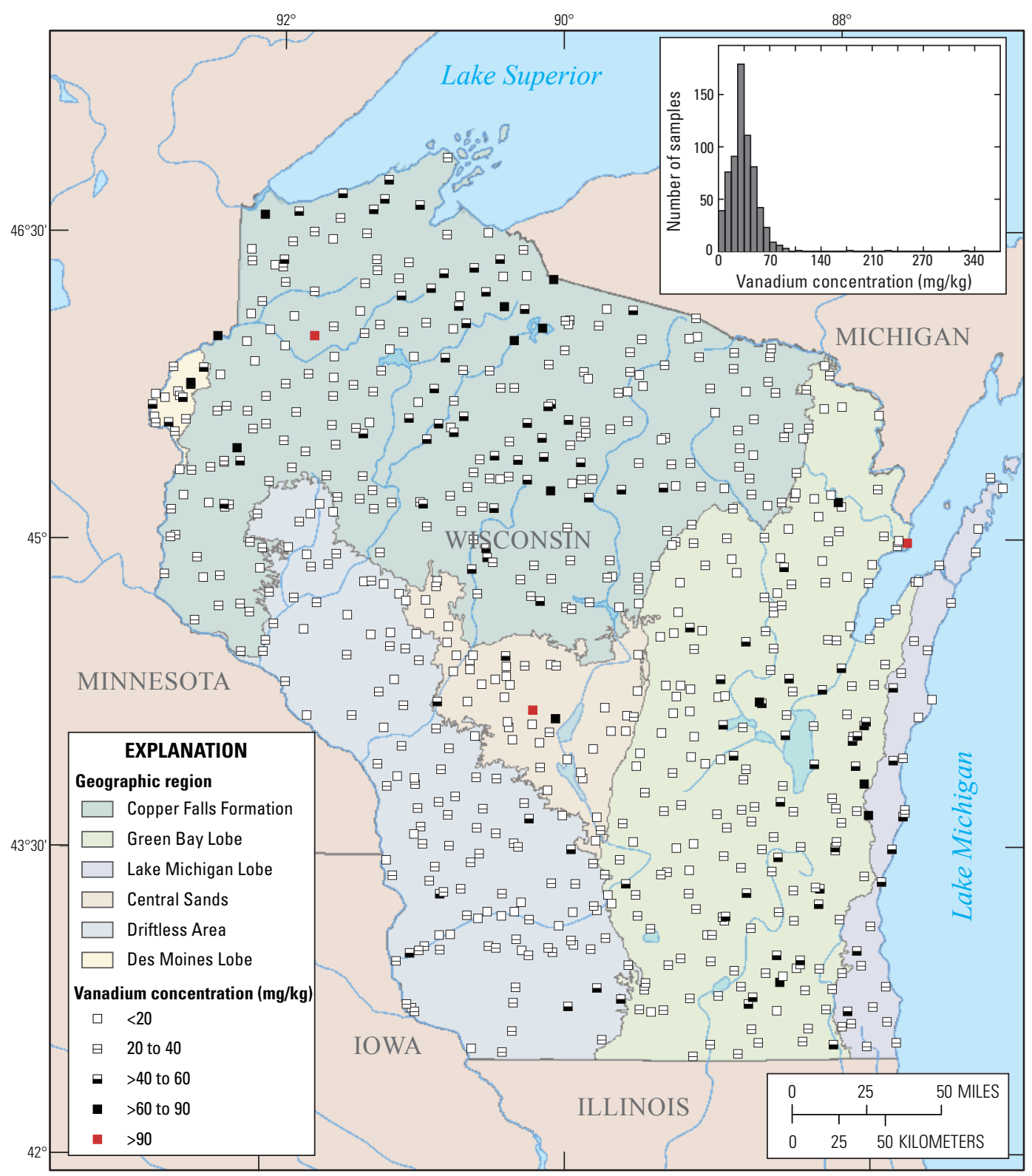

Figures 1-16. Spatial distribution of vanadium concentrations of surface soil samples in Wisconsin. The histogram in the figure gives the frequency distribution of the vanadium concentrations. The data displayed in both the map and the histogram include outliers that were removed prior to statistical analysis and are shown on the figure as red squares. 


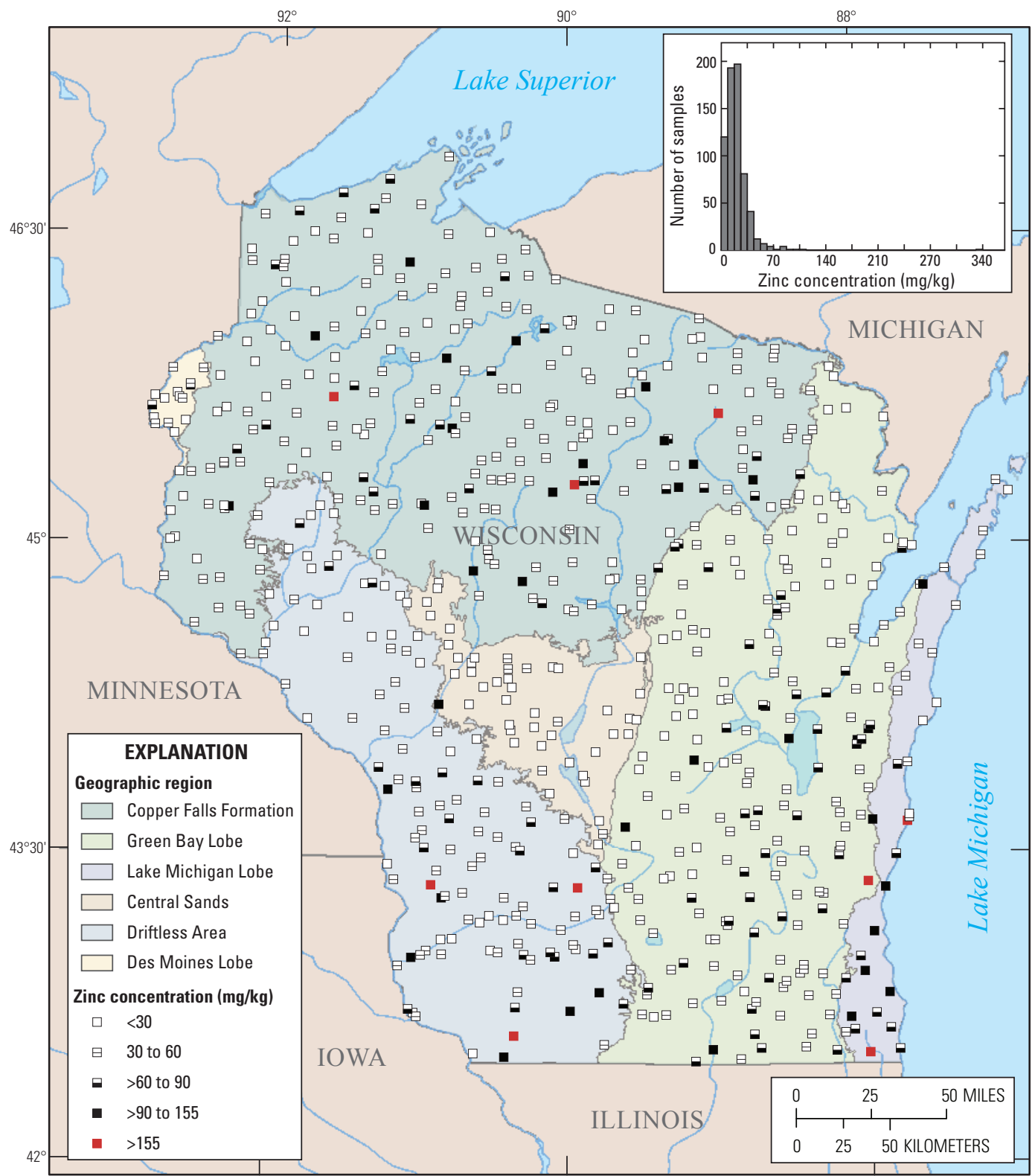

Figure 1-17. Spatial distribution of zinc concentrations of surface soil samples in Wisconsin. The histogram in the figure gives the frequency distribution of the zinc concentrations. The data displayed in both the map and the histogram include outliers that were removed prior to statistical analysis and are shown on the figure as red squares. 
Table 1-1. Complete dataset for arsenic baseline study.

This table, in Microsoft Excel format, is available for downloading at http://pubs.usgs.gov/sir/2011/5202/ 
Table 1-2. Statistical summary, including 95-percent upper confidence limit of the mean (95\% UCL), of trace element data from surface soil samples in Wisconsin. Summaries are for the entire dataset after outliers were removed. (*For the element molybdenum, the percentage of non-detect data was too high for the censored-data methods that were used in this report. None of the summary statistics were calculated for this element.)

[Statistics are for concentrations in milligrams per kilogram]

\begin{tabular}{|c|c|c|c|c|c|c|c|c|c|c|}
\hline $\begin{array}{c}\text { Trace } \\
\text { element }\end{array}$ & $\begin{array}{c}\text { Number } \\
\text { of samples }\end{array}$ & $\begin{array}{c}\text { Non-detects } \\
(\%)\end{array}$ & $\begin{array}{l}\text { Minimum } \\
\text { detected } \\
\text { value }\end{array}$ & $\begin{array}{l}\text { Maximum } \\
\text { detected } \\
\text { value }\end{array}$ & Median & Mean & $\begin{array}{l}95 \% \text { UCL of } \\
\text { the mean }\end{array}$ & $\begin{array}{c}\text { 90th } \\
\text { percentile }\end{array}$ & $\begin{array}{c}\text { 95th } \\
\text { percentile }\end{array}$ & $\begin{array}{c}\text { 99th } \\
\text { percentile }\end{array}$ \\
\hline Aluminum & 662 & 0 & 610 & 28,721 & 8,282 & 9,147 & 9,479 & 16,107 & 18,917 & 23,932 \\
\hline Arsenic & 654 & 32.3 & 1.0 & 8.3 & 1.8 & 2.3 & 2.4 & 4.3 & 5.6 & 7.4 \\
\hline Barium & 658 & 0 & 3.53 & 364 & 92.0 & 101 & 105 & 186 & 218 & 293 \\
\hline Calcium & 607 & 0 & 22.9 & 14,536 & 1,931 & 2,831 & 3,025 & 6,645 & 8,864 & 13,915 \\
\hline Cadmium & 642 & 38 & 0.10 & 1.07 & 0.15 & 0.23 & 0.25 & 0.53 & 0.68 & 0.98 \\
\hline Cobalt & 661 & 1.5 & 0.51 & 22.0 & 6.34 & 6.61 & 6.87 & 11.6 & 13.6 & 17.5 \\
\hline Chromium & 659 & 0 & 0.95 & 43.5 & 12.5 & 13.7 & 14.2 & 23.8 & 29.2 & 37.2 \\
\hline Copper & 655 & 0.5 & 0.50 & 35.4 & 6.52 & 8.38 & 8.78 & 17.0 & 22.0 & 29.0 \\
\hline Iron & 659 & 0 & 442 & 34,314 & 11,800 & 11,976 & 12,377 & 19,659 & 22,938 & 29,671 \\
\hline Magnesium & 633 & 0 & 66.3 & 8,290 & 1,769 & 2,103 & 2,204 & 4288 & 5251 & 6778 \\
\hline Manganese & 650 & 0 & 2.53 & 2,937 & 465 & 610 & 647 & 1363 & 1728 & 2450 \\
\hline Molybdenum* & 664 & 91 & 1.0 & 8.5 & - & - & - & - & - & - \\
\hline Nickel & 663 & 0.8 & 0.53 & 30.8 & 8.9 & 9.8 & 10.2 & 18.3 & 21.0 & 27.5 \\
\hline Lead & 648 & 0 & 1.48 & 51.6 & 11.3 & 13.5 & 14.1 & 24.6 & 33.0 & 46.6 \\
\hline Strontium & 653 & 0 & 0.50 & 54.5 & 11.5 & 13.6 & 14.2 & 25.8 & 36.2 & 45.9 \\
\hline Vanadium & 661 & 0 & 1.76 & 85.0 & 26.1 & 27.4 & 28.2 & 45.0 & 52.2 & 68.9 \\
\hline Zinc & 655 & 0 & 2.56 & 150 & 40.4 & 42.8 & 44.3 & 75.8 & 90.7 & 121.5 \\
\hline
\end{tabular}





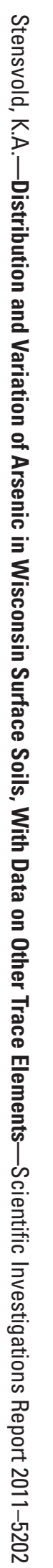

